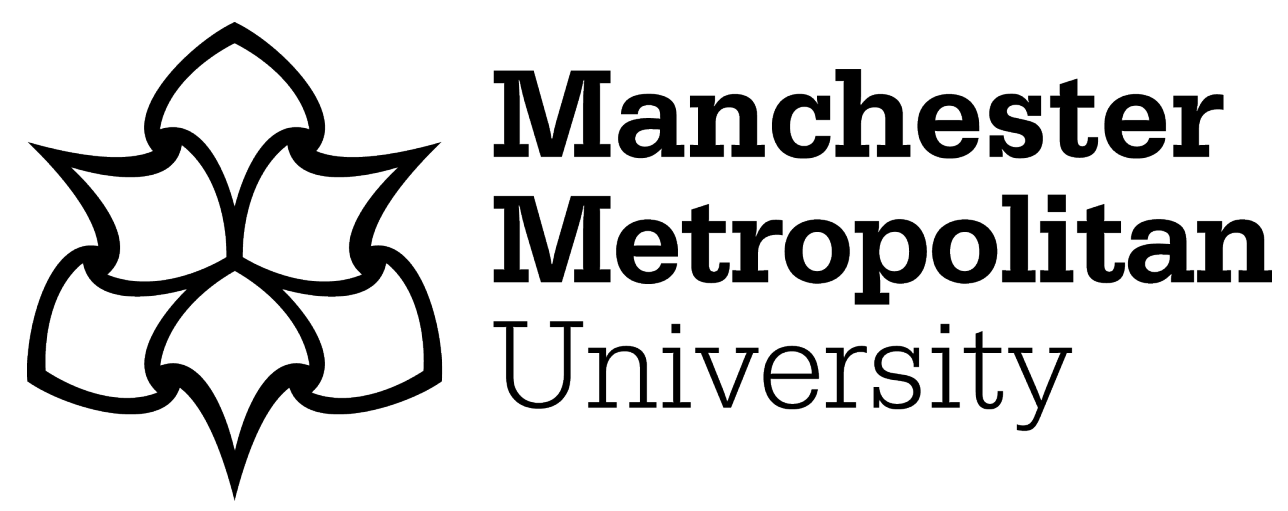

Vignesh, KR, Langley, SK, Gartshore, CJ, Borilović, I, Forsyth, CM, Rajaraman, G and Murray, KS (2018) Rationalizing the sign and magnitude of the magnetic coupling and anisotropy in dinuclear manganese(iii) complexes. Dalton Transactions, 47 (34). pp. 11820-11833. ISSN 1477-9226

Downloaded from: https://e-space.mmu.ac.uk/625953/

Version: Accepted Version

Publisher: Royal Society of Chemistry

DOI: https://doi.org/10.1039/c8dt01410h

Please cite the published version 


\title{
Rationalizing the Sign and Magnitude of the Magnetic Coupling and Anisotropy in Dinuclear Manganese(III) complexes \$
}

\author{
Kuduva R. Vignesh ${ }^{\mathrm{a}}$, Stuart K. Langley ${ }^{\mathrm{b}}$, Christopher J. Gartshorec, Ivana Borilovićc, Craig M. \\ Forsyth $^{c}$, Gopalan Rajaraman ${ }^{\mathrm{d} *}$ and Keith S. Murray ${ }^{\mathrm{c}^{*}}$
}

\begin{abstract}
We have synthesised twelve manganese(III) dinuclear complexes, 1-12, in order to understand the origin of magnetic exchange $(J)$ between the metal centres and the magnetic anisotropy $(D)$ of each metal ion using a combined experimental and theoretical approach. All twelve complexes contain the same bridging ligand environment of one $\mu$-oxo and two $\mu$ carboxylato, that helped us to probe how the structural parameters, such as bond distance, bond angle and especially Jahn-Teller dihedral angle affect the magnetic behaviour. Among the twelve complexes, we found ferromagnetic coupling for five and antiferromagnetic coupling for seven. DFT computed the $J$ and $a b$ initio methods computed the $D$ parameter, and are in general agreement with the experimentally determined values. The dihedral angle between the two Jahn-Teller axes of the constituent $\mathrm{Mn}^{\text {"II }}$ ions are found to play a key role in determining the sign of the magnetic coupling. Magnetostructural correlations are developed by varying the $\mathrm{Mn}-\mathrm{O}$ distance and the $\mathrm{Mn}-\mathrm{O}-\mathrm{Mn}$ angle to understand how the magnetic coupling changes upon these structural changes. Among the developed correlations, the Mn-O distance is found to be the most sensitive parameter that switches the sign of the magnetic coupling from negative to positive. The singleion zero-field spilitting of the $\mathrm{Mn}^{\prime \prime \prime}$ centres are found to be negative for complexes 1-11 and positive for complex $\mathbf{1 2}$. However, the zero-field spiliting of the $S=4$ state for the ferromagnetic coupled dimers is found to be positive, revealing a significant contribution from the exchange anisotropy - a parameter which has long been ignored as being too small to be effective.
\end{abstract}

\section{Introduction}

The synthesis of polynuclear coordination complexes containing multiple paramagnetic metal centres, coupled with the advancement in our understanding of the relationship between structure and magnetic behaviour is an area of current general interest. ${ }^{1}$ The magnetic exchange interaction mediated via a diamagnetic bridging ligand (magnetic super-exchange) plays a significant role in determining and understanding the magnetic properties of discrete polynuclear coordination complexes. ${ }^{1}$ It is therefore of great interest to be in a position to i) predict the sign and magnitude of magnetic super-exchange interaction based on structural data and ii) use this information to design new complexes which contain "favourable" magnetic exchange interactions which suit the needs of the problem. In order to achieve this goal many complexes must be studied and by comparing the observed magnetic behaviour (for example the exchange interaction) to the structural parameters, especially studying how small structural changes affect such behaviour, will therefore allow us to develop magneto-structural correlations, i.e. which structural parameters affect the magnetic properties. Of particular interest are structurally simple, small nuclearity compounds (di-, tri- or tetranuclear), which contain a small number of magnetic exchange pathways (one or two). The exchange mechanisms involved are influenced by many structural factors including, for example, the type of metal ion(s) (M) and bridging ligand(s) (L) employed, and the specific $M \cdots M$ and $M \cdots L$ bond distances and the $M \cdots L \cdots M$ and $M \cdots L \cdots L \cdots M$ angles in the molecule. ${ }^{1}$ Understanding the magnetostructural relationship in small compounds, such as di- and tri- nuclear paramagnetic complexes is important in understanding the magnetic behaviour of very large polymetallic complexes. In recent times, molecular magnetism has seen huge growth in the synthesis of molecules containing large numbers of metal ions because of their potential application in information storage, magnetic refrigeration, quantum computing and spintronics. ${ }^{2-10}$

The first example of a quantitative magneto-structural relationship was developed many years ago by Hatfield and Hodgson for a large family of di- $\mu-\mathrm{OH}$ bridged $\left\{\mathrm{Cu}_{2}{ }_{2}\right\}$ complexes, in which the magnetic exchange $(J)$ was found to be governed by the magnitude of the $\mathrm{Cu}$ $\mathrm{OH}-\mathrm{Cu}$ angle. ${ }^{11-14}$ Thereafter, magneto-structural correlations were also attempted and established for (dimeric) complexes containing other first row transition metal ions such as Fe ${ }^{I I I},{ }^{15-17} \mathrm{Cr}^{111},{ }^{18-21} \mathrm{Mn}^{1122}$ and $\mathrm{Mn}^{\text {III.23 }}$ In addition to experimental studies, theoretical methods based on density functional theory (DFT) have become important tools to compute the magnetic exchange interactions and develop magneto-structural correlations. ${ }^{24}$ These theoretical methods have provided excellent numerical estimates of $J$ values. One major advantage of the theoretical method is that the developed magneto-structural correlations on simplified model complexes will allow exploration of which parameters can change the sign and magnitude of $J$.

This paper details the synthesis and characterization of a family of dinuclear $\mathrm{Mn}^{\text {III }}$ complexes with carboxylato and oxo bridging ligands. Such species are known to occur in some metalloenzymes, such as $\mathrm{Mn}$ catalase, which is responsible for the disproportionation of $\mathrm{H}_{2} \mathrm{O}_{2} \cdot{ }^{25-27}$ To mimic this enzyme, several dinuclear $\mathrm{Mn}^{\prime \prime \prime}$ complexes with a $\left[\mathrm{Mn}_{2}(\mu-\mathrm{O})(\mu-\mathrm{RCOO})_{2}\right]^{2+}$ core have been reported 
in the literature, ${ }^{28-50}$ and, in some cases, they have been magnetically and structurally characterized. ${ }^{28-44}$ Due to its large single ion anisotropy, the Jahn-Teller distorted $\mathrm{Mn}^{\mathrm{III}}$ ion is the preferred d-block ion of choice for the synthesis of single-molecule magnets (SMMs). ${ }^{2-5,51}$ To design SMMs it is preferable to have strong ferromagnetic exchange between neighbouring metal centres and finding out what controls the magnitude and sign of the pairwise magnetic exchange is essential. Such prerequisites present a non-trivial synthetic challenge. Apart from exchange interaction, the magnetic anisotropy also plays a pivotal role in the design of SMMs. Due to the inherent Jahn-Teller distortion of $\mathrm{Mn}^{\text {III }}$ ions, the zero-field splitting (zfs) parameter is generally negative as desired for magnetic bistability in 0-D molecules and hence often display SMM behaviour. Although the magnitude of $D$ is smaller compared to other transition metal complexes, ${ }^{52-57}$ the Jahn-Teller elongation causes negative value of $D$ in the majority of the systems reported $^{58-60}$ and this offers a chance to ensure negative axial zfs. However, incorporation of more than one $\mathrm{Mn}^{\text {III }}$ ion does not enhance the magnitude of $D$ nor guarantee that the sign of $D$ will be negative. The SMM character is correlated to the orientation of single ion anisotropy and also the sign and strength of the magnetic exchange. This concept has been very little explored despite its importance in the design of novel $\mathrm{Mn}^{\text {III }}$ containing SMMs. In approaching these challenges, a family of twelve $\mathrm{Mn}^{\text {III }}$ dinuclear complexes have been synthesised with molecular formulae, minus solvate molecules, of $\left[\mathrm{Mn}^{\prime \prime \prime}{ }_{2} \mathrm{O}(4-\mathrm{CN}-\text { benz })_{2} \mathrm{Cl}_{2}(\text { bpy })_{2}\right]$ (1), $\left[\mathrm{Mn}^{\prime \prime \prime}{ }_{2} \mathrm{O}(\mathrm{Piv})_{2}(\mathrm{bpy})_{2} \mathrm{Cl}_{1.65}\left(\mathrm{H}_{2} \mathrm{O}\right)_{0.35}\right] \mathrm{Cl}_{0.35}$ (2), $\left[\mathrm{Mn}^{\prime \prime \prime}{ }_{2} \mathrm{O}(\mathrm{p} \text {-tol })_{2}(\mathrm{bpy})_{2} \mathrm{Cl}_{2}\right]$ and $\left[\mathrm{Mn}_{2}{ }_{2} \mathrm{O}(\mathrm{p} \text {-tol })_{2}(\text { bpy })_{2} \mathrm{Cl}\left(\mathrm{H}_{2} \mathrm{O}\right)\right] \mathrm{Cl} \quad$ (3), $\quad\left[\mathrm{Mn}_{2}^{\prime \prime \prime} \mathrm{O}(3,4\right.$-difluorobenz $\left.)_{2}(\text { bpy })_{2} \mathrm{Cl}_{2}\right]$ (4), $\left[\mathrm{Mn}^{\prime \prime \prime}{ }_{2} \mathrm{O}(4-\mathrm{CN}-\text { benz })_{2}(\text { bpy })_{2}\left(\mathrm{H}_{2} \mathrm{O}\right)_{2}\right]\left(\mathrm{NO}_{3}\right)_{2} \quad$ (5), $\left[\mathrm{Mn}_{2}{ }_{2} \mathrm{O}(2,3,4,5,6-\mathrm{F}-\text { benz })_{2}(\text { bpy })_{2}\left(\mathrm{H}_{2} \mathrm{O}\right)_{2}\right]\left(\mathrm{NO}_{3}\right)_{2} \quad(6), \quad\left[\mathrm{Mn}_{2} \mathrm{OI}{ }_{2} \mathrm{O}\left(4-\mathrm{NO}_{2}-\right.\right.$ benz $\left.)_{2}(\text { bpy })_{2}\left(\mathrm{NO}_{3}\right)\left(\mathrm{H}_{2} \mathrm{O}\right)\right]\left(\mathrm{NO}_{3}\right)_{2} \quad$ (7), $\quad\left[\mathrm{Mn}_{2}{ }_{2} \mathrm{O}(4-\mathrm{Br}-\right.$ benz $\left.)_{2}(\text { bpy })_{2}\left(\mathrm{NO}_{3}\right)\left(\mathrm{H}_{2} \mathrm{O}\right)\right]\left(\mathrm{NO}_{3}\right)_{2}(8),\left[\mathrm{Mn}_{2} \mathrm{O}(4-\mathrm{CN}-\text { benz })_{2}(\mathrm{bpy})_{2}\left(\mathrm{NO}_{3}\right)_{2}\right]$ and $\left[\mathrm{Mn}_{2} \mathrm{O}(4-\mathrm{CN}-\text { benz })_{2}(\text { bpy })_{2}\left(\mathrm{NO}_{3}\right)\left(\mathrm{H}_{2} \mathrm{O}\right)\right] \mathrm{NO}_{3} \quad(9), \quad\left[\mathrm{Mn}_{2}^{\prime \prime \prime}{ }_{2} \mathrm{O}(\mathrm{o}-\right.$ tol $\left.)_{2}(\text { bpy })_{2}\left(\mathrm{NO}_{3}\right)_{2}\right] \quad(\mathbf{1 0}), \quad\left[\mathrm{Mn}_{2} \mathrm{II} \mathrm{O}(2,6 \text {-difluoro-benz })_{2}(\mathrm{bpy})_{2}\left(\mathrm{ClO}_{4}\right)_{2}\right]$ (11) $\left[\mathrm{Mn} \mathrm{III}_{2} \mathrm{O}(\text { benz })_{2}\left(\mathrm{~N}_{3}\right)_{2}(\text { bpy })_{2}\right]$ (12), $\{4-\mathrm{CN}$-benz = 4-cyanobenzoate; piv = pivalate; $p$-tol $=$ para-toluate; 3,4-difluoro-benz $=3,4$ difluorobenzoate; 2,3,4,5,6-F-benz $=$ 2,3,4,5,6-pentaflurobenzoate; 4-NO $\mathrm{NO}_{2}$-benz = 4-nitrobenzoate; 4-Br-benz = 4-bromobenzoate; o-tol = ortho-toluate; 2,6-difluoro-benz = 2,6-difluorobenzoate; benz= benzoate; bpy $=2,2$ '-bipyridyl $\}$. All complexes contain the same bridging ligand environment and thus are ideal to probe how structure affects magnetic behaviour. It was found that the magnetic exchange interaction between the $\mathrm{Mn}^{\text {III-}}-\mathrm{Mn}^{\text {"II }}$ ions varied significantly, with experimental values ranging from -5.69 to +10.1 $\mathrm{cm}^{-1}$. We have used DFT as a tool to rationalize these magnetic exchange interactions and have developed several magnetostructural correlations. The origin of magnetic anisotropy in the dinuclear $\left\{\mathrm{Mn}_{2}{ }_{2}\right\}$ complexes is also discussed.

\section{Experimental section}

\section{X-ray crystallography}

X-ray measurements for 1, 2, 4-8, 10 and 12 were performed at 123(2) K using a Bruker Smart Apex X8 diffractometer with Mo K $\alpha$ radiation. The data collection and integration were performed within SMART and SAINT+ software programs, and corrected for absorption using the Bruker SADABS program. Data for 1 were treated as a non-merohedral twin. The orientation matrices of the two components were identified using the program CELL NOW ${ }^{61}$ and corresponded to a 180 deg rotation about reciprocal axis 001 . Integration and scaling were performed within the Apex2 program suite in conjunction with TWINABS (Bruker AXS, 2014). Measurements for compound 3 were performed at 100(2) $\mathrm{K}$ at the Australian synchrotron MX1 beam-line. ${ }^{62}$ Data collection and integration were performed in Blu-Ice ${ }^{63}$ and $\mathrm{XDS}^{64}$ software programs. Measurements for compounds $\mathbf{9}$ and $\mathbf{1 1}$ were collected with an Oxford Diffraction Supernova diffractometer using $\mathrm{Cu} \mathrm{K \alpha}$ radiation. The data collection and data reduction were performed using CrysAlisPro ${ }^{65}$ absorption corrections were applied using a multiscan method. 66 The compounds were solved by direct methods (SHELX-2016), and refined (SHELX-2016) by full least-matrix leastsquares on all $\mathrm{F}^{2}$ data. ${ }^{61,67}$ Hydrogen atoms were included for coordinated and lattice water molecules where possible. In many cases, the lattice solvents (including water molecules) were poorly defined and were therefore eliminated from the model and the residual electron density was accounted for using PLATON SQUEEZE for complexes 2, 4, 11 and $\mathbf{1 2 . 6 8}$ Crystallographic parameters are given in Table 1. CCDC numbers complex 1, 1836203, complex 2, 1835303, complexes 3-12: 1835439-1835448.

\section{Magnetic measurements}

The magnetic susceptibility measurements were carried out on a Quantum Design SQUID magnetometer MPMS-XL 7 operating between 1.8 and $300 \mathrm{~K}$ for dc-applied fields ranging from $0-5 \mathrm{~T}$. Microcrystalline samples were dispersed in Vaseline in order to avoid torquing of the crystallites. The magnetometer was calibrated by use of a standard palladium pellet of accurately known susceptibility (Quantum Design) and checked by use of chemical calibrants such as $\mathrm{CuSO}_{4} .5 \mathrm{H}_{2} \mathrm{O}$ or $\mathrm{Hg}\left[\mathrm{Co}(\mathrm{NCS})_{4}\right]$. The sample mulls were contained in a calibrated gelatine capsule held at the centre of a drinking straw that was fixed at the end of the sample rod.

\section{Computational Details Exchange Calculation}

The DFT calculations combined with a Broken Symmetry (BS) approach $^{69}$ have been employed to compute the $J$ parameter for each dinuclear complex. The BS method has a proven record of yielding good numerical estimate of $J$ constants for a variety of complexes ${ }^{70-75}$ including dinuclear ${ }^{60,} 76-78$ and polynuclear complexes. ${ }^{70,}$ 79-84 The DFT calculations were performed using the B3LYP functional ${ }^{85}$ with the Gaussian 09 suite of programs. ${ }^{86}$ We have used the Ahlrich's ${ }^{87-88}$ triple- - -quality basis set for $\mathrm{Mn}$ as well as for the rest of the atoms. The following Hamiltonian is used to estimate the magnetic exchange interaction $(J)$ between the $\mathrm{Mn}(\mathrm{III})$ centres for complexes 1-12.

$$
\widehat{H}=-2 J\left(S_{M n 1} S_{M n 2}\right) \ldots \ldots \ldots \ldots \ldots \ldots \ldots \ldots . . . . . . . . . . . . . .(1)
$$


The $\mathrm{PHI}^{89}$ program was used for the simulation/fitting of magnetic susceptibilities. All magneto-structural correlations have been calculated by varying the specific structural parameters and performed single point calculation on the modified structure.

\section{Zero-Field Splitting calculation}

The ZFS parameter $(D)$ of all complexes are computed in the $a b$ initio framework, where all the calculations are based on the complete active space self-consistent theory (CASSCF) using ORCA 3.0 software. ${ }^{90}$ The spin-orbit coupling (SOC) contributions in the $a b$ initio framework were obtained using second-order perturbation theory as well as employing the effective Hamiltonian approach which enables calculations of all matrix elements to be made of the anisotropic spin Hamiltonian from the $a b$ initio energies and wave functions numerically. The RI approximation with secondary TZV/C and SV/C correlation fitting basis sets were used along with increased integration grids. Inclusion of excited states is key for the accurate estimation of the zfs parameter $(D)$ in transition metal ion complexes $^{91}$ which we have therefore employed. In the case of the dinuclear systems studied, we have taken 8 active electrons $(2 \mathrm{x}$ $\mathrm{Mn}^{\prime \prime \prime}$ metal ions) in 10 metal based d-orbitals (five from each $\mathrm{Mn}^{\prime \prime \prime}$ ion) for our calculation (CAS $(8,10)$ ) and we have computed ten nonets, fifty septet and fifty quintet states for the estimation of the cluster ZFS. The calculations have been performed using the TZVPP basis set along with the TZVP/C correlation fitting basis set for $\mathrm{Mn}^{\text {III }}$ ions, while the TZVP basis set has been employed for the rest of the atoms. Four active electrons occupying five metal d-based orbitals of $\mathrm{Mn}^{\text {III }}$ have been taken as the active space (CAS $\left.(4,5)\right)$ for the estimation of the single ion anisotropy of each $\mathrm{Mn}^{\text {III }}$ ion in all complexes.

Table 1. X-ray crystallographic data for $1-12$ 


\begin{tabular}{|c|c|c|c|c|c|c|c|c|c|c|c|c|}
\hline & 1 & 2 & 3 & 4 & 5 & 6 & 7 & 8 & 9 & 10 & 11 & 12 \\
\hline $\begin{array}{c}\text { Formula sum } \\
\text { M, } \text { gmol }^{-1}\end{array}$ & $\begin{array}{c}\mathrm{Mn}_{2} \mathrm{C}_{44} \mathrm{H}_{35} \\
\mathrm{Cl}_{2} \mathrm{O}_{5} \mathrm{~N}_{10} \\
964.60\end{array}$ & $\begin{array}{c}\mathrm{Mn}_{2} \mathrm{C}_{30} \mathrm{H}_{34} \\
\mathrm{Cl}_{2} \mathrm{O}_{6} \mathrm{~N}_{4} \\
727.39\end{array}$ & $\begin{array}{c}\mathrm{Mn}_{2} \mathrm{C}_{40} \mathrm{H}_{36.5} \\
\mathrm{Cl}_{2} \mathrm{O}_{7.25} \mathrm{~N}_{4} \\
868.5\end{array}$ & $\begin{array}{c}\mathrm{Mn}_{2} \mathrm{C}_{34} \mathrm{H}_{22} \\
\mathrm{Cl}_{2} \mathrm{~F}_{4} \mathrm{O}_{5} \mathrm{~N}_{4} \\
823.33\end{array}$ & $\mid \begin{array}{c}\mathrm{Mn}_{2} \mathrm{C}_{40} \mathrm{H}_{34} \\
\mathrm{O}_{13} \mathrm{~N}_{10} \\
972.65\end{array}$ & $\begin{array}{c}\mathrm{Mn}_{2} \mathrm{C}_{36} \mathrm{H}_{23} \\
\mathrm{~F}_{10} \mathrm{O}_{13} \mathrm{~N}_{7} \\
1063.49\end{array}$ & $\begin{array}{c}\mathrm{Mn}_{2} \mathrm{C}_{34} \mathrm{H}_{25} \\
\mathrm{O}_{15.5} \mathrm{~N}_{8} \\
903.50\end{array}$ & $\begin{array}{c}\mathrm{Mn}_{2} \mathrm{C}_{34} \mathrm{Br}_{2} \\
\mathrm{H}_{26} \mathrm{O}_{12} \mathrm{~N}_{6} \\
980.31\end{array}$ & $\begin{array}{c}\mathrm{Mn}_{2} \mathrm{C}_{36} \mathrm{H}_{526} \\
\mathrm{O}_{12} \mathrm{~N}_{8} \\
872.53\end{array}$ & $\begin{array}{c}\mathrm{Mn}_{2} \mathrm{C}_{40} \mathrm{H}_{36} \\
\mathrm{O}_{11} \mathrm{~N}_{8} \\
914.65\end{array}$ & $\begin{array}{c}\mathrm{Mn}_{2} \mathrm{C}_{38} \mathrm{H}_{32} \\
\mathrm{Cl}_{2} \mathrm{~F}_{4} \mathrm{O}_{14} \mathrm{~N}_{4} \\
1025.45\end{array}$ & $\begin{array}{c}\mathrm{Mn}_{2} \mathrm{C}_{34} \mathrm{H}_{26} \\
\mathrm{O}_{5} \mathrm{~N}_{10} \\
764.53\end{array}$ \\
\hline Crystal system & Monoclinic & Monoclinic & Triclinic & Monoclinic & Monoclinic & Monoclinic & Monoclinic & Monoclinic & Monoclinic & Triclinic & Tetragonal & Monoclinic \\
\hline Space group & $P 2_{1} / c$ & $P 21 / n$ & $P-1$ & $P 2_{1} / n$ & $C 2 / c$ & $P 2_{1} / c$ & $C 2 / c$ & $P 2_{1} / c$ & $C c$ & $P-1$ & $1-4$ & $\mathrm{C} 2 / \mathrm{c}$ \\
\hline$a / \AA ̊$ & $16.1214(5)$ & $11.1015(7)$ & $14.911(3)$ & $10.199(2)$ & $23.502(18)$ & $11.003(2)$ & $35.1308(13)$ & $17.7484(12)$ & $35.1374(5)$ & $13.3895(12)$ & $23.5015(2)$ & $16.2539(10)$ \\
\hline$b / \AA$ & $29.3047(9)$ & $21.3140(14)$ & $16.531(3)$ & $25.127(5)$ & $36.337(3)$ & $35.389(7)$ & $9.9470(3)$ & 22.1971(13) & $10.0176(2)$ & $13.4068(11)$ & $23.5015(2)$ & $25.9567(17)$ \\
\hline$c / \AA ̊$ & $9.5424(3)$ & $16.8311(10)$ & $19.012(4)$ & $16.301(3)$ & $10.6262(7)$ & $21.596(4)$ & $20.8627(9)$ & $10.0271(8)$ & $20.7404(3)$ & $14.0228(11)$ & $15.9233(2)$ & $9.5595(5)$ \\
\hline$\alpha / \operatorname{deg}$ & 90 & 90 & $100.59(3)$ & 90 & 90 & 90 & 90 & 90 & 90 & $102.762(4)$ & 90 & 90 \\
\hline B/deg & $92.4480(10)$ & $94.581(3)$ & $110.42(3)$ & 99.93(3) & $110.520(2)$ & $98.85(3)$ & $100.6020(10)$ & ) $104.886(3)$ & $96.7670(10)$ & $98.430(4)$ & 90 & 101.585(3) \\
\hline$\gamma /$ deg & 90 & 90 & $93.96(3)$ & 90 & 90 & 90 & 90 & 90 & 90 & $118.206(4)$ & 90 & 90 \\
\hline$V / \AA^{3}$ & $4504.0(2)$ & $3969.8(4)$ & 4271.9(15) & $4114.8(14)$ & $8499.0(11)$ & $8309(3)$ & $7165.9(5)$ & $3817.7(5)$ & $7249.6(2)$ & 2069.2(3) & 8794.76(19) & 3951.0(4) \\
\hline$T / K$ & $123(2)$ & $123(2)$ & $100(2)$ & $123(2)$ & $123(2)$ & $123(2)$ & $123(2)$ & $123(2)$ & $123(2)$ & $123(2)$ & $123(2)$ & $123(2)$ \\
\hline Z & 4 & 4 & 4 & 4 & 8 & 8 & 8 & 4 & 8 & 2 & 8 & 4 \\
\hline$\rho$, calc $\left[\mathrm{g} \mathrm{cm}^{-3}\right]$ & 1.423 & 1.217 & 1.350 & 1.329 & 1.494 & 1.697 & 1.673 & 1.706 & 1.599 & 1.468 & 1.549 & 1.285 \\
\hline$\lambda^{[b]} / \AA$ & 0.71073 & 0.71073 & 0.71079 & 0.71073 & 0.71073 & 0.71073 & 0.71073 & 0.71073 & 1.54184 & 0.71073 & 1.54184 & 0.71073 \\
\hline Data Measured & 17978 & 19359 & 64859 & 68641 & 11268 & 110155 & 28105 & 21988 & 14850 & 16517 & 32225 & 13310 \\
\hline Ind. Reflns & 8145 & 8065 & 16724 & 9806 & 4528 & 14452 & 10953 & 7726 & 9259 & 7373 & 9016 & 4488 \\
\hline $\mathrm{R}_{\text {int }}$ & 0.0646 & 0.0705 & 0.1165 & 0.0398 & 0.0403 & 0.1092 & 0.0536 & 0.0719 & 0.0348 & 0.0496 & 0.0387 & 0.0531 \\
\hline $\begin{array}{l}\text { Reflns with I } \\
\qquad \mathrm{I}>2 \sigma(\mathrm{I})\end{array}$ & 7083 & 3849 & 10356 & 8205 & 3282 & 10693 & 6800 & 4615 & 9428 & 5122 & 7668 & 2491 \\
\hline Parameters & 573 & 410 & 1070 & 460 & 652 & 1221 & 581 & 544 & 1058 & 552 & 579 & 231 \\
\hline Restraints & 12 & 0 & 6 & 0 & 31 & 12 & 15 & 24 & 8 & 0 & 34 & 3 \\
\hline $\begin{array}{l}\mathrm{R}_{1}[\mathrm{cc}(\mathrm{I}>2 \sigma(\mathrm{I})) \\
\mathrm{WR}_{2}{ }^{[\mathrm{cc}]}(\text { all data) }\end{array}$ & $\begin{array}{l}0.0428 \\
0.1079 \\
\end{array}$ & $\begin{array}{l}0.0647 \\
0.2080\end{array}$ & $\begin{array}{l}0.0863 \\
0.2747 \\
\end{array}$ & $\begin{array}{l}0.0467 \\
0.1342 \\
\end{array}$ & $\begin{array}{l}0.0450 \\
0.1063\end{array}$ & $\begin{array}{l}0.0977 \\
0.2223\end{array}$ & $\begin{array}{l}0.0519 \\
0.1284\end{array}$ & $\begin{array}{l}0.0712 \\
0.1719 \\
\end{array}$ & $\begin{array}{l}0.0379 \\
0.1011 \\
\end{array}$ & $\begin{array}{l}0.0485 \\
0.1265\end{array}$ & $\begin{array}{l}0.0622 \\
0.1926 \\
\end{array}$ & $\begin{array}{l}0.0589 \\
0.1750\end{array}$ \\
\hline goodness of fit & 1.069 & 0.961 & 1.027 & 1.038 & 1.019 & 1.159 & 1.006 & 1.080 & 1.044 & 0.986 & 1.030 & 1.003 \\
\hline \begin{tabular}{|c|} 
Largest \\
residuals/ e Á -3
\end{tabular} & $\begin{array}{l}0.687 \\
-0.479 \\
\end{array}$ & $\begin{array}{l}0.515 \\
-0.617\end{array}$ & $\begin{array}{l}1.409 \\
-1.427 \\
\end{array}$ & $\begin{array}{l}1.414 \\
-0.629 \\
\end{array}$ & $\begin{array}{l}0.580 \\
-0.493 \\
\end{array}$ & $\begin{array}{l}0.939 \\
-1.124 \\
\end{array}$ & $\begin{array}{l}0.582 \\
-0.470\end{array}$ & $\begin{array}{l}1.060 \\
-0.855 \\
\end{array}$ & $\begin{array}{l}0.400 \\
-0.492 \\
\end{array}$ & $\begin{array}{l}0.634 \\
-0.480 \\
\end{array}$ & $\begin{array}{l}0.481 \\
-0.787\end{array}$ & $\begin{array}{l}0.423 \\
-0.517 \\
\end{array}$ \\
\hline
\end{tabular}

\section{General Information}

All reactions were carried out under aerobic conditions. Chemicals and solvents were obtained from commercial sources and used without further purification. 


\section{Synthesis of complexes.}

[Mn'II' $\left.{ }_{2} \mathrm{O}(4-\mathrm{CN} \text {-benz })_{2}(\text { bpy })_{2} \mathrm{Cl}_{2}\right] \cdot 4 \mathrm{MeCN}$ (1). $\mathrm{MnCl}_{2} \cdot 4 \mathrm{H}_{2} \mathrm{O}$ (0.1 g, 0.5 $\mathrm{mmol}$ ) was dissolved in MeCN $(20 \mathrm{~mL})$, followed by the addition of 4-cyanobenzoic acid $(0.29 \mathrm{~g}, 2.0 \mathrm{mmol})$, tetrabutylammonium permanganate $(0.05 \mathrm{~g}, 0.15 \mathrm{mmol})$ and 2,2'-bipyridyl $(0.1 \mathrm{~g}, 0.64$ $\mathrm{mmol}$ ) which resulted in a brown solution. The solution was stirred for 2 hours after which time a brown precipitate appeared. The precipitate was removed and the solution was allowed to slowly evaporate. Within 4 - 5 days dark brown crystals of 1 had appeared, in approximate yield of $80 \%$ (crystalline product). Anal. Calculated (found) for 1: $\mathrm{Mn}_{2} \mathrm{C}_{44} \mathrm{H}_{36} \mathrm{O}_{5} \mathrm{~N}_{10} \mathrm{Cl}_{2}$ : C, 54.73(54.99); $\mathrm{H}, 3.76$ (4.67); $\mathrm{N}$, 14.51 (13.73)

$\left.\left[\mathrm{Mn}_{2}{ }_{2} \mathrm{O} \text { (Piv) }\right)_{2}(\mathrm{bpy})_{2} \mathrm{Cl}_{1.65}\left(\mathrm{H}_{2} \mathrm{O}\right)_{0.35}\right] \mathrm{Cl}_{0.35} \cdot \mathrm{H}_{2} \mathrm{O}_{0.65}$ (2). The synthetic method for 1 was followed, but pivalic acid $(0.2 \mathrm{~g}, 2 \mathrm{mmol})$ was used in place of 4-cyanobenzoic acid. Dark brown crystals of 2 appeared within 5 - 7 days, in approximate yield of $67 \%$ (crystalline product). Anal. Calculated (found) for 2: $\mathrm{Mn}_{2} \mathrm{C}_{30} \mathrm{H}_{34} \mathrm{O}_{6} \mathrm{~N}_{4} \mathrm{Cl}_{2}: \mathrm{C}, 49.54$ (49.32); H, 4.71 (7.99); N, 6.70 (6.94).

$\left[\mathrm{Mn}_{2}^{\prime \prime \prime}{ }_{2} \mathrm{O}(\mathrm{p} \text {-tol })_{2}(\mathrm{bpy})_{2} \mathrm{Cl}_{2}\right]$ and $\left[\mathrm{Mn}^{\prime \prime \prime}{ }_{2} \mathrm{O}(\mathrm{p} \text {-tol })_{2}(\mathrm{bpy})_{2} \mathrm{Cl}\left(\mathrm{H}_{2} \mathrm{O}\right)\right] \mathrm{Cl} \cdot \mathrm{p}$ tolH:1.5 $\mathrm{H}_{2} \mathrm{O}$ (3). The synthetic method for 1 was followed but paratoluic acid $(0.27 \mathrm{~g}, 2 \mathrm{mmol})$ was used in place of 4-cyanobenzoic acid. Dark brown crystals of $\mathbf{3}$ appeared within 6 - 8 days, in approximate yield of $75 \%$ (crystalline product). Anal. Calculated (found) for 3: $\mathrm{Mn}_{2} \mathrm{C}_{40} \mathrm{H}_{36.5} \mathrm{O}_{7.25} \mathrm{~N}_{4} \mathrm{Cl}_{2}$ : C, 55.57 (54.97); $\mathrm{H}, 4.08$ (4.43); N, 6.48 (6.56).

[ $\left.\mathrm{Mn}_{2}{ }_{2} \mathrm{O}(3,4 \text {-difluoro-benz })_{2}(\mathrm{bpy})_{2} \mathrm{Cl}_{2}\right]$ (4). The synthetic method for 1 was followed but 3,4-difluorobenzoic acid $(0.32 \mathrm{~g}, 2 \mathrm{mmol})$ was used in place of 4-cyanobenzoic acid. Dark brown crystals of 4 appeared within 5-7 days, in approximate yield of $60 \%$ (crystalline product). Anal. Calculated (found) for 4: $\mathrm{Mn}_{2} \mathrm{C}_{34} \mathrm{H}_{22} \mathrm{O}_{5} \mathrm{~N}_{4} \mathrm{Cl}_{2} \mathrm{~F}_{4}: \mathrm{C}$, 49.60 (49.23); H, 2.69 (2.34); N, 6.80 (6.62).

$\left[\mathrm{Mn}_{2}^{\prime \prime \prime}{ }_{2} \mathrm{O}(\text { benz-4-CN })_{2}(\text { bpy })_{2}\left(\mathrm{H}_{2} \mathrm{O}\right)_{2}\right]\left(\mathrm{NO}_{3}\right)_{2} \cdot 2 \mathrm{MeCN}(5) \mathrm{Mn}\left(\mathrm{NO}_{3}\right)_{2} \cdot 6 \mathrm{H}_{2} \mathrm{O}$ $(0.14 \mathrm{~g}, 0.5 \mathrm{mmol})$ was dissolved in $\mathrm{MeCN}(20 \mathrm{~mL})$, followed by the addition of 4-cyanobenzoic acid $(0.29 \mathrm{~g}, 2.0 \mathrm{mmol})$, tetrabutylammonium permanganate $(0.05 \mathrm{~g}, 0.15 \mathrm{mmol})$ and 2,2 'bipyridyl $(0.1 \mathrm{~g}, 0.64 \mathrm{mmol})$, which resulted in a brown solution. This solution was stirred for 2 hours after which time the solvent was removed to give a brown oil. This was re-dissolved in $\mathrm{MeOH}(20 \mathrm{~mL})$ and the solution was allowed to evaporate slowly. Within 5 - 7 days' dark brown crystals of $\mathbf{5}$ had appeared, in approximate yield of $70 \%$ (crystalline product). Anal. Calculated (found) for 5: $\mathrm{Mn}_{2} \mathrm{C}_{40} \mathrm{H}_{34} \mathrm{O}_{13} \mathrm{~N}_{10}$ : C, 49.40 (48.26); H, 3.52 (3.11); N, 14.40 (14.29).

$\left[\mathrm{Mn}^{\prime \prime \prime}{ }_{2} \mathrm{O}(2,3,4,5,6-\mathrm{F}-\text { benz })_{2}(\text { bpy })_{2}\left(\mathrm{H}_{2} \mathrm{O}\right)_{2}\right]\left(\mathrm{NO}_{3}\right)_{2} \cdot \mathrm{MeCN}$ (6). The synthetic method for $\mathbf{5}$ was followed but 2,3,4,5,6pentafluorobenzoic acid $(0.42 \mathrm{~g}, 2 \mathrm{mmol})$ was used in place of 4cyanobenzoic acid. Dark brown crystals of 6 appeared within 8-10 days, in approximate yield of $54 \%$ (crystalline product). Anal.
Calculated (found) for 6: $\mathrm{Mn}_{2} \mathrm{C}_{36} \mathrm{H}_{23} \mathrm{O}_{13} \mathrm{~N}_{7} \mathrm{~F}_{10}: \mathrm{C}, 40.73$ (40.91); $\mathrm{H}$, 2.18 (2.47); N, 9.24 (9.56).

$\left.\left[\mathrm{Mn}^{\prime \prime \prime}{ }_{2} \mathrm{O}(\text { benz-4-NO})_{2}\right)_{2}(\text { bpy })_{2}\left(\mathrm{NO}_{3}\right)_{1.5}\left(\mathrm{H}_{2} \mathrm{O}\right)_{0.5}\right]\left(\mathrm{NO}_{3}\right)_{0.5} \quad$ (7). The synthetic method for 5 was followed but 4-nitrobenzoic acid $(0.34$ $\mathrm{g}, 2 \mathrm{mmol}$ ) was used in place of 4-cyanobenzoic acid. Dark brown crystals of 7 appeared within 4 - 5 days, in approximate yield of 65 $\%$ (crystalline product). Anal. Calculated (found) for 7: $\mathrm{Mn}_{2} \mathrm{C}_{34} \mathrm{H}_{25} \mathrm{O}_{15.5} \mathrm{~N}_{8}$ : C, 44.80 (44.89); H, 2.76 (2.67); N, 12.29 (12.42).

\section{$\left[\mathrm{Mn}_{2}{ }_{2} \mathrm{O} \mathrm{O}(4-\mathrm{Br}-\mathrm{Benz})_{2}(\mathrm{bpy})_{2}\left(\mathrm{NO}_{3}\right)_{1.5}\left(\mathrm{H}_{2} \mathrm{O}\right)_{0.5}\right]\left(\mathrm{NO}_{3}\right)_{0.5} \cdot 0.5 \mathrm{H}_{2} \mathrm{O}$ (8).}

The synthetic method for $\mathbf{5}$ was followed but 4-bromobenzoic acid $(0.4 \mathrm{~g}, 2 \mathrm{mmol})$ was used in place of 4-cyanobenzoic acid. Dark brown crystals of 8 appeared within 5 - 7 days, in approximate yield of $45 \%$ (crystalline product). Anal. Calculated (found) for 8 $\mathrm{Mn}_{2} \mathrm{C}_{34} \mathrm{H}_{26} \mathrm{O}_{12} \mathrm{~N}_{6} \mathrm{Br}_{2}$ : C, 41.66 (41.61); $\mathrm{H}, 2.67$ (2.77); N, 8.57 (8.90).

$\left[\mathrm{Mn}_{2} \mathrm{O}(4-\mathrm{CN}-\text { benz })_{2}(\text { bpy })_{2}\left(\mathrm{NO}_{3}\right)_{2}\right]$ and $\left[\mathrm{Mn}_{2} \mathrm{O}(4-\mathrm{CN}\right.$ benz $\left.)_{2}(\text { bpy })_{2}\left(\mathrm{NO}_{3}\right)\left(\mathrm{H}_{2} \mathrm{O}\right)\right] \mathrm{NO}_{3} \cdot \mathrm{H}_{2} \mathrm{O}$ (9). The synthetic method for 1 was followed but $\mathrm{Mn}\left(\mathrm{NO}_{3}\right)_{2} \cdot 6 \mathrm{H}_{2} \mathrm{O}(0.14 \mathrm{~g}, 0.5 \mathrm{mmol})$ was used in place of $\mathrm{MnCl}_{2} \cdot 4 \mathrm{H}_{2} \mathrm{O}$. Dark brown crystals of 9 appeared within 5 - 7 days, in approximate yield of $65 \%$ (crystalline product). Anal. Calculated (found) for 9: $\mathrm{Mn}_{2} \mathrm{C}_{36} \mathrm{H}_{26} \mathrm{O}_{12} \mathrm{~N}_{8}$ : C, 49.56 (49.34); $\mathrm{H}, 3.00$ (2.91); N, 12.84 (12.55).

$\left[\mathrm{Mn}_{2}^{\prime \prime \prime} \mathrm{O}(\mathrm{o}-\mathrm{tol})_{2}(\mathrm{bpy})_{2}\left(\mathrm{NO}_{3}\right)_{2}\right] \cdot 2 \mathrm{MeCN}$ (10). The synthetic method for 5 was followed but ortho-toluic acid $(0.27 \mathrm{~g}, 2 \mathrm{mmol})$ was used in place of 4-CN-benzoic acid. Dark brown crystals of 10 appeared within 3 - 4 days, in approximate yield of $57 \%$ (crystalline product). Anal. Calculated (found) for 10: $\mathrm{Mn}_{2} \mathrm{C}_{40} \mathrm{H}_{36} \mathrm{O}_{11} \mathrm{~N}_{8}: \mathrm{C}, 52.88$ (52.59); $H, 3.33$ (3.17); N, 12.33 (12.79).

$\left[\mathrm{Mn}_{2}^{\prime \prime \prime} \mathrm{O}(2,6 \text {-difluoro-benz })_{2}(\text { bpy })_{2}\left(\mathrm{ClO}_{4}\right)_{2}\right] \cdot \mathrm{Et}_{2} \mathrm{O}$ (11). The synthetic method for 1 was followed but $\mathrm{Mn}\left(\mathrm{ClO}_{4}\right)_{2} \cdot \mathrm{xH}_{2} \mathrm{O}$ was used in place of $\mathrm{MnCl}_{2} .4 \mathrm{H}_{2} \mathrm{O}$ and 2,6-difluorobenzoic acid $(0.32 \mathrm{~g}, 2 \mathrm{mmol})$ in place of 4-cyanobenzoic acid. Dark brown crystals of $\mathbf{1 1}$ appeared within 7 - 9 days, in approximate yield of $45 \%$ (crystalline product). Anal. Calculated (found) for 11: $\mathrm{Mn}_{2} \mathrm{C}_{38} \mathrm{H}_{32} \mathrm{O}_{14} \mathrm{~N}_{4} \mathrm{Cl}_{2} \mathrm{~F}_{4}: \mathrm{C}$, 44.51 (44.72); $\mathrm{H}$, 3.15 (3.22); N, 5.46 (5.31).

[Mn ${ }_{2}^{\prime \prime}{ }_{2} \mathrm{O}$ (benz $\left.)_{2}\left(\mathrm{~N}_{3}\right)_{2}(\text { bpy })_{2}\right]$ (12). $\mathrm{MnCl}_{2} \cdot 4 \mathrm{H}_{2} \mathrm{O}(0.1 \mathrm{~g}, 0.5 \mathrm{mmol})$ was dissolved in MeCN (20 mL), followed by the addition of benzoic acid (0.24 g, $2.0 \mathrm{mmol})$, sodium azide $(0.065 \mathrm{~g}, 1 \mathrm{mmol})$, tetrabutylammonium permanganate $(0.05 \mathrm{~g}, 0.15 \mathrm{mmol})$ and $2,2^{\prime}-$ bipyridyl $(0.1 \mathrm{~g}, 0.64 \mathrm{mmol})$, which resulted in a brown solution. This solution was stirred for 2 hours after which time the solution was allowed to evaporate slowly. Within 5 - 7 days' dark brown crystals of 12 had appeared, in approximate yield of $70 \%$ (crystalline product). Anal. Calculated (found) for 12: $\mathrm{Mn}_{2} \mathrm{C}_{34} \mathrm{H}_{26} \mathrm{O}_{5} \mathrm{~N}_{10}$ : C, 53.42 (53.27); H, 3.43 (3.37); N, 18.32 (18.61).

\section{Results and Discussion}




\section{Synthesis and crystal structures}

Compounds $\mathbf{1}$ - $\mathbf{1 2}$ were synthesized using the general method of reacting $\mathrm{MnX}_{2} \cdot \mathrm{nH}_{2} \mathrm{O}\left(\mathrm{X}=\mathrm{Cl}, \mathrm{NO}_{3}\right.$ and $\left.\mathrm{ClO}_{4}\right)$ with a substituted benzoic acid, tetrabutylammonium permanganate and 2,2'-bipyridyl in acetonitrile at ambient temperature, using a $\sim 3: 12: 1: 3$ stoichiometric ratio of reagents, respectively. This method was adapted from previous work on $\mathrm{Mn}^{\text {III }}$ dimers. ${ }^{50}$ Adding $\mathrm{NaN}_{3}$ to the above reaction condition with benzoic acid yielded complex $12 .{ }^{30}$ It should be noted that several other complexes of varying nuclearity and valence could also be isolated under the reaction conditions employed above. The most common being several tetranuclear complexes which could be isolated from varying the ratio of the reactants and solvent used. These compounds are found to be structurally related to the twelve compounds reported in this work. ${ }^{92}$

From the single crystal $X$-ray diffraction experiments, we find that compounds 1, 6 and 8 crystallize in the monoclinic space group, $\mathrm{P} 21 / \mathrm{c}$, compound $\mathbf{2}$ and $\mathbf{4}$ crystallize in the monoclinic space group, $P 2_{1} / n$, compounds $\mathbf{3}$ and $\mathbf{1 0}$ crystallize in the triclinic space group, $P$ 1, compounds $\mathbf{5}, \mathbf{7}$ and $\mathbf{1 2}$ crystallize in the monoclinic space group, $\mathrm{C} 2 / \mathrm{c}$, compound $\mathbf{9}$ crystallizes in the monoclinic space group $\mathrm{Cc}$ and compound $\mathbf{1 1}$ crystallizes in the tetragonal space group, I-4. The single crystal X-ray diffraction data reveals that all twelve compounds are homovalent dinuclear complexes containing two

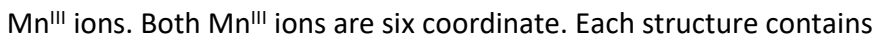
the same bridging motif between the $\mathrm{Mn}^{\text {III }}$ ions - consisting of two carboxylate ligands and one oxide ( $\left.\mathrm{O}^{2-}\right)$ ligand (Figures $1, \mathrm{~S} 1$ and $\mathrm{S} 2$ ). Further to this, at each $\mathrm{Mn}^{\text {III }}$ site (for all complexes) a chelating 2,2bipyridine ligand is found. These bridging and chelating ligands account for five of the coordination sites. The sixth coordination site is made up of various terminal ligands, which differ between complexes $\mathbf{1}$ - 12. These terminal sites consist of $\mathrm{Cl}^{-}, \mathrm{H}_{2} \mathrm{O},\left[\mathrm{NO}_{3}\right]^{-}$, $\left[\mathrm{ClO}_{4}\right]^{-}$or $\left[\mathrm{N}_{3}\right]^{-}$ligands and depend on the reaction conditions employed. For $\mathbf{1}-\mathbf{4}$ the $\mathrm{Cl}^{-}$ion is found terminal at both $\mathrm{Mn}^{\text {"II }}$ sites. We also note that crystallographic disorder is found at one $\mathrm{Mn}^{\text {III }}$ site for $2\left(\mathrm{Cl}\right.$ and $\left.\mathrm{H}_{2} \mathrm{O}\right)$ modelled at $0.65 \mathrm{Cl}: 0.35 \mathrm{H}_{2} \mathrm{O}$ occupancy and the asymmetric unit for 3 contains two unique $\left\{\mathrm{Mn}_{2}\right\}$ molecules, the second of which contains one terminal $\mathrm{Cl}^{-}$ion and a terminal $\mathrm{H}_{2} \mathrm{O}$ ligand. For $\mathbf{5}$ and $\mathbf{6}$ a $\mathrm{H}_{2} \mathrm{O}$ molecule is found terminal at each $\mathrm{Mn}^{\text {"II }}$ site (for 6 two chemically identical molecules are present in the asymmetric unit), whereas for $7-9$ a combination of $\mathrm{H}_{2} \mathrm{O}$ molecules and $\left[\mathrm{NO}_{3}\right]^{-}$ions are found. For $\mathbf{7}$ and $\mathbf{8}$ crystallographic disorder is found at one of the $\mathrm{Mn}^{\prime \prime \prime}$ sites with a $\left[\mathrm{NO}_{3}\right]^{-}$ion and a $\mathrm{H}_{2} \mathrm{O}$ molecule occupying the same position, modelled at 50:50 occupancy. Complex 9 contains two unique $\left\{\mathrm{Mn}^{\prime \prime \prime}{ }_{2}\right\}$ molecules in the asymmetric unit - one $\left\{\mathrm{Mn}^{\prime \prime \prime}{ }_{2}\right\}$ dimer contains a terminal $\left[\mathrm{NO}_{3}\right]^{-}$ion at each $\mathrm{Mn}^{\text {III }}$ site and the other consists of one $\left[\mathrm{NO}_{3}\right]^{-}$ion and one $\mathrm{H}_{2} \mathrm{O}$. For 5 - 9, non-coordinating $\left[\mathrm{NO}_{3}\right]^{-}$counter anions are present to balance the charge. For 10, 11 and 12, a nitrate anion, a perchlorate anion and an azide anion is found at each $\mathrm{Mn}^{\text {III }}$ site, respectively. The $\mathrm{Mn}^{\text {III }}$ centres for $\mathbf{1}$ - $\mathbf{1 1}$ display Jahn-Teller (JT) distorted octahedral geometries, which are axially elongated, with a $\left[\mathrm{N}_{2} \mathrm{O}_{3} \mathrm{Cl}\right]$ or $\left[\mathrm{N}_{2} \mathrm{O}_{4}\right]$ or $\left[\mathrm{N}_{3} \mathrm{O}_{3}\right]$ coordination sphere. Compound $\mathbf{1 2}$, on the other hand, displays an axially compressed Jahn-Teller geometry. The Jahn-Teller axes are found to align perpendicular to each other (to a first approximation) which are derived from an $\mathrm{O}$ atom of a carboxylate group and a terminal ligand. The two main JT dihedral angles ( $\mathrm{X}-\mathrm{Mn} 1-\mathrm{Mn} 2-\mathrm{X}$ where $\mathrm{X}=$ terminal ligand sites and $\mathrm{O}-\mathrm{Mn1}-\mathrm{Mn2}-\mathrm{O}$ where $\mathrm{O}$ is the oxygen atom of carboxylate group) is found to range from $74.8^{\circ}$ to $109.5^{\circ}$. Selected bond distances and angles for 1-12 are given in Tables S1 and S2. The Mn-O, Mn-N and $\mathrm{Mn}-\mathrm{Cl}$ bond distances are in the range 1.777-2.283 $\AA, 2.044-2.136$ $\AA$ and $2.448-2.560 \AA$, respectively. The $\mathrm{Mn} \cdots \mathrm{Mn}$ distance for $1-12$ ranges from $3.128-3.188 \AA$, and the $\mathrm{Mn}-\left(\mu_{2}-\mathrm{O}^{2-}\right)-\mathrm{Mn}$ bond angle is in the range of $122.4-126.6^{\circ}$.

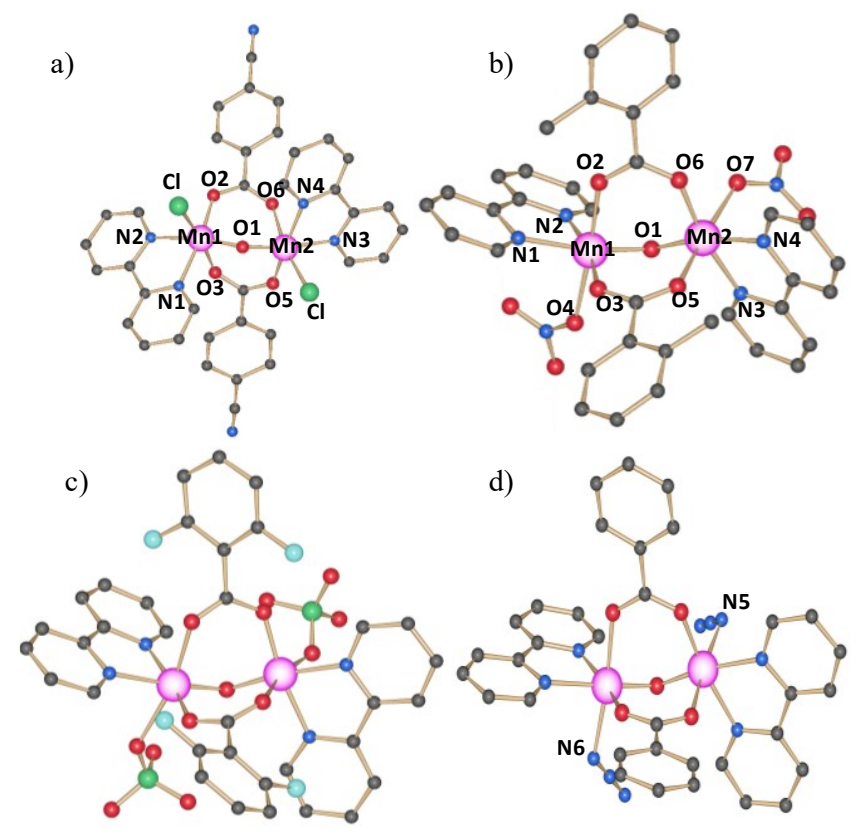

Figure 1. The molecular structure of complex (a) 1, (b) 10, (c) 11 and (d) 12. The solvent and $\mathrm{H}$ atoms are omitted for clarity. Colour scheme; $\mathrm{Mn}^{\text {III }}$, pink; O, red; $\mathrm{N}$, blue; C, light grey; $\mathrm{Cl}$, green; F, cyan. (N.B. Other structures are given in the ESI)

\section{Magnetic Studies. Comparison of experimental and DFT calculated} data.

In order to probe the magnetic properties, direct current (dc) magnetic susceptibility measurements were performed on polycrystalline samples in the temperature range $2-300 \mathrm{~K}$, with an applied magnetic field of $1 \mathrm{~T}$. Isothermal magnetization plots are also recorded in magnetic fields between $0-5 \mathrm{~T}$. The $\chi_{M} T$ values at $300 \mathrm{~K}$ are close to the expected value of $6.0 \mathrm{~cm}^{3} \mathrm{~mol}^{-1} \mathrm{~K}$ for two $S=$ 2 ions with those displaying ferromagnetic coupling $(\mathbf{3}, \mathbf{4}, \mathbf{6}, \mathbf{9}, \mathbf{1 2})$ being a bit larger than $6.0 \mathrm{~cm}^{3} \mathrm{~mol}^{-1} \mathrm{~K}$; Figure 2 . It is observed that significant variations are found in the temperature dependent behaviour observed for the $\chi_{M} T$ product across the complexes 1 12. This is due to the different exchange parameters and the corresponding spin state energy levels, and thus this family of compounds, which possess only one exchange interaction, with similar bridging ligands, viz. $\left\{\mu\left(\mathrm{RCO}_{2}\right)_{2}(\mu\right.$-oxo $\left.)\right\}$, provides an ideal 
vehicle for probing the reasons that can cause such differences. Fitting of the experimental magnetic data was performed using the $\mathrm{PHI}$ program ${ }^{89}$ to extract the nature and the magnitude of the magnetic exchange interactions $\left(J_{\text {exp }}\right)$ within each cluster. From the fits it is found that the magnitude of the experimentally determined magnetic exchange interaction varies from antiferromagnetic (-5.7 $\left.\mathrm{cm}^{-1}\right)$ to ferromagnetic $\left(9.8 \mathrm{~cm}^{-1}\right)$ (Table $\left.2-J_{\text {exp }}\right)$.
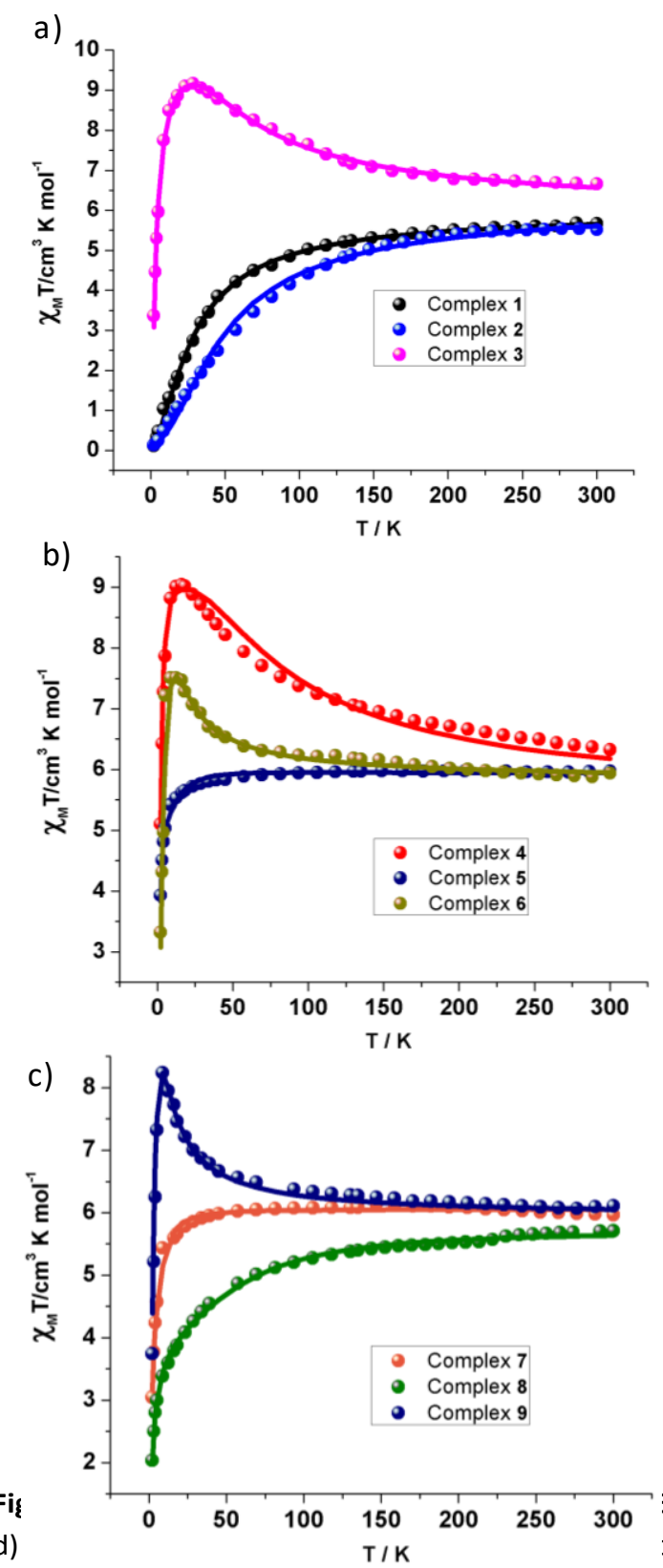

d)

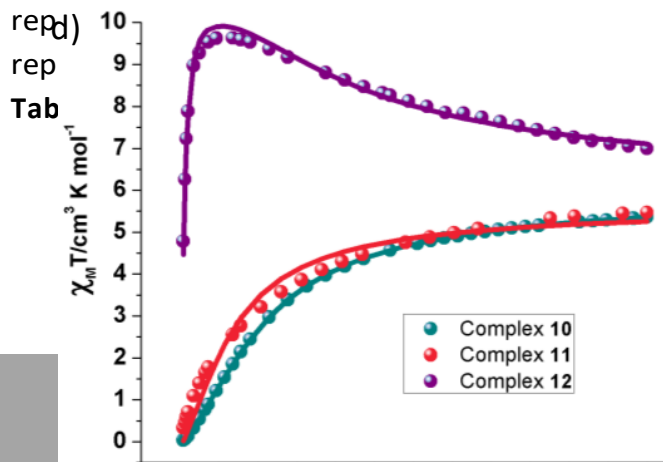

coupling constant $\left(J\right.$ in $\left.\mathrm{cm}^{-1}\right), g$ and zero field splitting $\left(D\right.$ in $\mathrm{cm}^{-1}$ of single-ion) values for 1-12.

\begin{tabular}{|c|c|c|c|c|c|c|}
\hline \multirow{2}{*}{} & \multicolumn{3}{|c|}{ Experiment } & \multicolumn{3}{c|}{ Calculated } \\
\cline { 2 - 7 } & $J$ & $g_{\mathrm{Mn}}$ & $D_{\mathrm{Mn}}$ & $J$ & $g_{\mathrm{Mn}}$ & $D_{\mathrm{Mn}}$ \\
\hline $\mathbf{1}$ & -0.2 & 1.97 & -3.1 & -1.2 & 1.99 & -3.0 \\
$\mathbf{2}$ & -5.1 & 2.04 & -2.1 & -2.8 & 1.98 & -2.9 \\
$\mathbf{3}$ & 5.5 & 1.99 & -4.2 & 10.9 & 1.93 & -3.1 \\
$\mathbf{4}$ & 7.4 & 1.90 & -1.1 & 9.7 & 1.91 & -3.0 \\
$\mathbf{5}$ & -0.1 & 1.99 & -2.9 & -1.1 & 2.02 & -3.1 \\
$\mathbf{6}$ & 1.1 & 1.97 & -5.6 & 0.7 & 1.98 & -3.3 \\
$\mathbf{7}$ & -0.2 & 2.01 & -5.5 & -0.5 & 2.00 & -3.0 \\
$\mathbf{8}$ & -0.1 & 1.95 & -4.5 & -2.4 & 2.00 & -2.9 \\
$\mathbf{9}$ & 1.0 & 1.99 & -4.3 & 3.2 & 1.95 & -3.2 \\
$\mathbf{1 0}$ & -5.7 & 2.00 & -2.8 & -5.7 & 2.00 & -3.3 \\
$\mathbf{1 1}$ & -3.6 & 1.94 & -0.8 & -9.7 & 2.12 & -3.2 \\
$\mathbf{1 2}$ & 9.8 & 2.00 & 3.9 & 19.2 & 1.97 & 3.7 \\
\hline
\end{tabular}
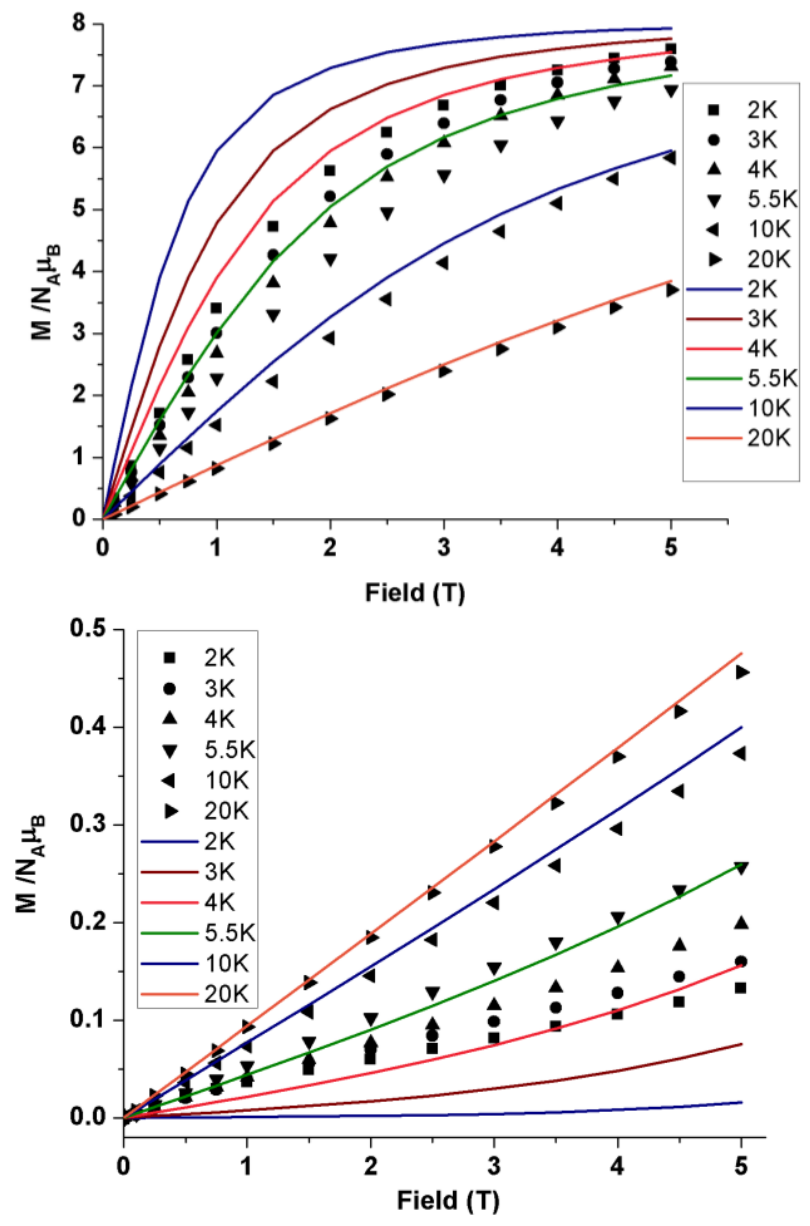

Figure 3. $M$ vs. $\mathrm{H}$ isotherms for (top) 3 and (bottom) 10 at temperatures 2 (top), 3, 4, 5.5, 10 and 20 (bottom) K. The black shapes are experimental data and the coloured lines are fits of the experimental data.

Jlour circles ur solid lines ted exchange
DFT calculations were then employed to determine the exchange coupling parameter and these values are given in Table 2 along with the experimental estimates. While the sign of magnetic exchange is reproduced in all cases compared to 
experiments, variation in the magnitude of the $J$ is noted across the structures. The DFT calculations predict that seven of the complexes $(\mathbf{1}, \mathbf{2}, \mathbf{5}, \mathbf{7}, \mathbf{8}, \mathbf{1 0}$ and $\mathbf{1 1})$ display antiferromagnetic exchange interactions, whereas for complexes 3, 4, 6, 9 and 12, DFT predicts ferromagnetic exchange interactions. The magnitude of the exchange is found to vary significantly with values ranging from $-9.7 \mathrm{~cm}^{-1}$ (complex 11) to $+19.2 \mathrm{~cm}^{-1}$ (complex 12). The calculated magnetization data also afford satisfactory fits to the experimental $M$ vs. $H$ data for 1-12 (see Figure 3 for complexes 3 and 10).

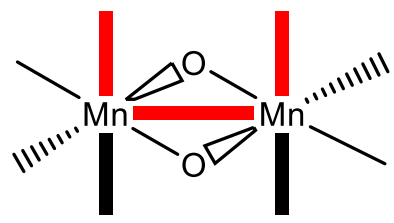

type I

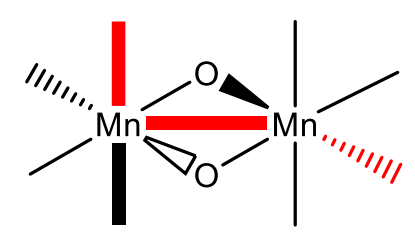

type III

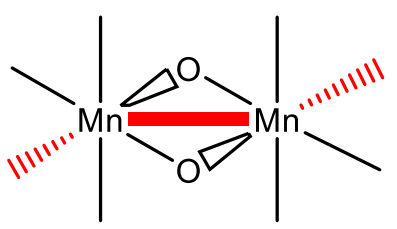

type II

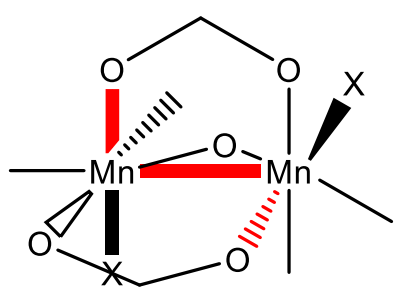

type IIIb
Figure 4. Schematic illustrating the three types (I-III) of JT orientations observed in previously reported $\mu$-OR bridged [ $\left.\mathrm{Mn}^{\prime I_{2}}\right]$ dimers. ${ }^{60}$ Type (IIIb) is observed in our $\mu-\mathrm{O}^{2-}$ bridged [ $\left[\mathrm{Mn}_{2}{ }^{\prime \prime \prime}\right]$ dimers. The red/black bold lines show the JT dihedral angle.

Considering the method proposed by Tuchagues and co-workers, ${ }^{93}$ doubly (one atom) bridged $\mathrm{Mn}^{\text {III }}$ dinuclear complexes are classified into three different types based on the orientation of the axially elongated Jahn-Teller axes, denoted type-I, type-II and type-III by Berg et.al. ${ }^{60}$ In type-I complexes the Jahn-Teller (JT) axes are parallel to each other but perpendicular to the bridging plane, whereas in type-II complexes the JT axes are parallel to each other and the bridging plane. In type-III complexes the JT axes are perpendicular to each other with one axis lying parallel while the other one perpendicular to the bridging plane. ${ }^{60}$ It has been reported that Type-I complexes display moderately strong antiferromagnetic magnetic exchange interactions $\left(-8.2\right.$ to $\left.-15.5 \mathrm{~cm}^{-1}\right)$, type-II complexes display weak ferro- and antiferromagnetic exchange interactions $\left(-1.7\right.$ to $\left.+6.3 \mathrm{~cm}^{-1}\right)$ and type-III complexes are found to show moderately strong ferromagnetic exchange $\left(+6.3\right.$ to $9.9 \mathrm{~cm}^{-}$ 1). ${ }^{60}$ Using this classification scheme for $\mathrm{Mn}^{\text {III }}$ di- $\mu$-alkoxo dimers, Berg et.a $/ 60$ have tested forty-five complexes and found that, to date, only two complexes belong to the type-III category. The typeIII complexes are rare due to their requirement of a low level of symmetry. Here, complexes 1-12 are $\mu$-oxo bridged and can be categorized as type-III, however the JT axes are not part of the single atom bridges. Thus we classify these structures as variant of type-III and termed them as type-IIIB and are expected to show moderate ferro- and antiferromagnetic exchange interactions, which is found to be the case (Table 2).

To understand the nature and magnitude of the exchange interaction observed in 1-12, overlap integrals have been analysed. Generally, in dinuclear complexes the net exchange interaction has two parts: (i) an antiferromagnetic $J_{\mathrm{AF}}$ part arising from overlap

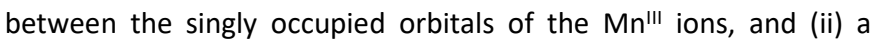
ferromagnetic term, $J_{F}$ arising due to orbital orthogonality, in addition to the effective "cross-interaction"59-60 between singly occupied molecular orbitals (SOMO) and the empty $d$-orbitals. Here, for the DFT computed magnetic exchange interaction for the complexes in which antiferromagnetic behaviour is predicted $(\mathbf{1}, \mathbf{2}$, $5,7,8,10$ and 11), the major contributor to the $J_{\mathrm{AF}}$ term is the overlap between the $d_{\mathrm{xz}}$ or $d_{\mathrm{yz}}$ orbitals. (For e.g. See Tables S4, S5 and S9 of 1, 2 and 5, respectively in the ESI). In these complexes, as the strength of orbital overlap is significant, the $J$ values are large. On the other-hand, for the complexes possessing ferromagnetic exchange $(\mathbf{3}, 4,6,9$ and $\mathbf{1 2})$, the $d_{\mathrm{xz}}$ or $d_{\mathrm{yz}}$ orbital overlap values are small and the orthogonality between the SOMOs is observed, hence, a larger contribution from the $J_{F}$ term is expected leading to a net ferromagnetic coupling (See Tables S6-S8, S10, S11 and S12 in ESI).

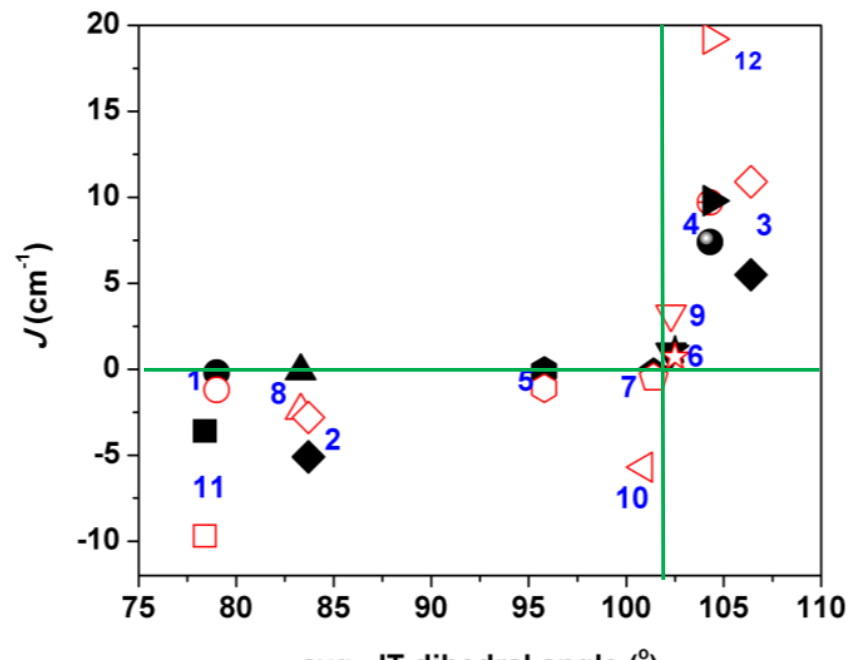

avg. JT dihedral angle $\left({ }^{\circ}\right)$

Figure 5. Correlating the averaged JT dihedral angle and exchange coupling constants in 1-12. The closed shapes represent experimental $J$ values and the open shapes represent DFT $J$ values.

We have also observed that the JT dihedral angle, i.e. the angle of $\mathrm{O} / \mathrm{X}-\mathrm{Mn} 1-\mathrm{Mn} 2-\mathrm{X} / \mathrm{O}$, plays a pivotal role - where, $\mathrm{X}$ is the bonding atom of the terminal ligand (i.e. $\mathrm{Cl}, \mathrm{O}$ or $\mathrm{N}$ ) and $\mathrm{O}$ is the $\mathrm{O}$-atom of the bridging carboxylate group. The average of the two main dihedral angles is $79.0,83.7,106.4,104.3,95.8,102.3,101.4,83.3$, $102.3,100.9,78.4$ and $104.4^{\circ}$ for $\mathbf{1}-\mathbf{1 2}$, respectively. From the data we find that when the averaged JT dihedral angle is larger than $\sim 102^{\circ}$, the exchange interaction is found to be ferromagnetic, whereas angles less than $102^{\circ}$ results in antiferromagnetic exchange (See Tables 2, S1 and S2 and Figure 5). The largest ferromagnetic coupling parameter predicted from DFT is for $\mathbf{1 2}$ $\left(+19.2 \mathrm{~cm}^{-1}\right)$, which displays the second largest averaged JT dihedral angle $\left(104.7^{\circ}\right)$, while the largest antiferromagnetic coupling 
determined for $\mathbf{1 1}\left(-9.7 \mathrm{~cm}^{-1}\right)$ has the smallest averaged JT dihedral angle $\left(78.3^{\circ}\right)$. Complex $\mathbf{3}$ has the largest averaged dihedral angle $\left(106.4^{\circ}\right)$, however, we find it has the second largest ferromagnetic coupling, which indicates (as expected) more than one "parameter" influences the exchange interaction. Moreover, the smallest ferromagnetic $\left(+0.7 \mathrm{~cm}^{-1}\right)$ and antiferromagnetic coupling $(-0.5 \mathrm{~cm}$ $\left.{ }^{1}\right)$ observed in 6 and 7, respectively reveal "borderline" averaged dihedral angles of $\sim 102^{\circ}$.

Since all the axially elongated JT axes align with the O-atom of the carboxylate group, we have modelled two of the complexes in order to understand the role, if any, the carboxylate group plays in influencing the magnitude of the magnetic coupling constants (See Figure 6). For this, we have taken out the aromatic ring of a carboxylate group from complexes $\mathbf{1 0}$ and $\mathbf{1 2}$ (considered as models 10a, $\left[\mathrm{Mn}^{\prime \prime \prime}{ }_{2} \mathrm{O}\right.$ (o-tol) $\left.\left(\mathrm{H}_{2} \mathrm{O}\right)_{2}(\text { bpy })_{2}\left(\mathrm{NO}_{3}\right)_{2}\right]$ and 12a $\left[\mathrm{Mn}_{2}{ }_{2} \mathrm{O}\right.$ (benz) $\left(\mathrm{H}_{2} \mathrm{O}\right)_{2}$ $\left.\left.\left(\mathrm{N}_{3}\right)_{2}(\mathrm{bpy})_{2}\right]\right)$. Similarly, we removed the aromatic ring from both the carboxylate group and constructed model 10b, $\left[\mathrm{Mn}_{2} \mathrm{O}\left(\mathrm{H}_{2} \mathrm{O}\right)_{4}(\mathrm{bpy})_{2}\left(\mathrm{NO}_{3}\right)_{2}\right]$ and 12b $\left[\mathrm{Mn}_{2} \mathrm{II}_{2} \mathrm{O}\left(\mathrm{H}_{2} \mathrm{O}\right)_{4}\left(\mathrm{~N}_{3}\right)_{2}(\mathrm{bpy})_{2}\right]$. When going from one carboxylate group (10a and 12a) to no carboxylate group (10b and $\mathbf{1 2 b}$ ) complexes, the magnitude of the coupling constants decreases but no sign change compared to the parent complexes 10 and 12 occur $\left(-5.7 \mathrm{~cm}^{-1} \rightarrow-4.5 \mathrm{~cm}^{-1} \rightarrow-2.5\right.$ $\mathrm{cm}^{-1}$ for $10 \rightarrow 10 \mathrm{a} \rightarrow 10 \mathrm{~b}$, and $+19.2 \mathrm{~cm}^{-1} \rightarrow+16.8 \mathrm{~cm}^{-1} \rightarrow+1.4 \mathrm{~cm}^{-1}$ for $12 \rightarrow 12 a \rightarrow 12 b$ ). This clearly indicates that the different carboxylate groups are responsible for the varying magnitude of the coupling constants, however, the JT dihedral angle decides the sign

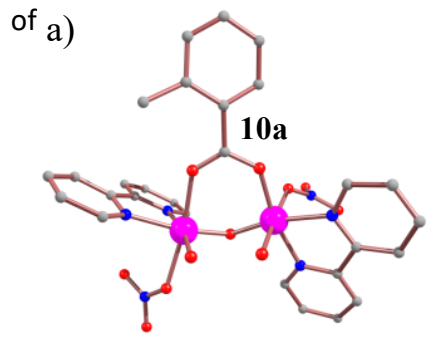

b)

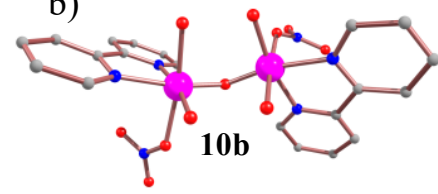

d)
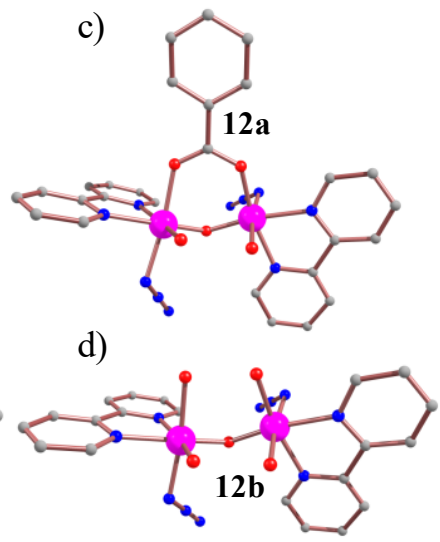

Figure 6. The structures of the model complexes (a) 10a, (b) 10b, (c) $12 \mathrm{a}$ and (d) $\mathbf{1 2 b}$. The $\mathrm{H}$ atoms are omitted for clarity. Color scheme; $\mathrm{Mn}^{\prime \prime \prime}$, pink; O, red; N, blue; C, light grey.

The computed spin density diagrams for the high spin state of $\mathbf{1 - 2}$, 6-7, 11 and 12 are shown in Figure 7. The spin density on $\mathrm{Mn}^{\text {III }}$ is computed to be 3.75-3.90 for all complexes and this suggests spin delocalization occurs between the $\mathrm{Mn}^{\mathrm{III}}$ ion and the coordinated atoms. The bridging $\mu_{2}-\mathrm{O}^{2-}$ ligand gains a spin density of $0.02-0.07$ via spin delocalization. The coordinated carboxylate 0 -atoms gain a spin density of $0.01-0.04$. The coordinated bipyridyl $\mathrm{N}$-atom has a spin density of $\sim-0.03$. In complexes $1-4$, the coordinated $\mathrm{Cl}^{-}$atom gains a spin density of $0.1-0.11$. In complexes $\mathbf{5 - 1 0}$, the coordinated O-atom from $\left(\mathrm{NO}_{3}\right)^{-}$- or $\mathrm{H}_{2} \mathrm{O}$ has a spin density of $\sim 0.01$. In complex 11 , the coordinated $\mathrm{O}$-atom from $\left(\mathrm{ClO}_{4}\right)^{-}$gains a spin density of $\sim 0.01$. In complex 12 , the coordinated $\mathrm{N}$-atom from the azide ligand has a spin density of -0.02 and the uncoordinated $\mathrm{N}$ atom gains a spin density of $\sim 0.09$. Generally, $\mathrm{Mn}^{\prime \prime \prime}$ ions are found to exhibit both spin delocalization and polarization, with spin delocalization dominating along the JT elongated axis. ${ }^{60,82}$ This trend is also observed for 1-12.
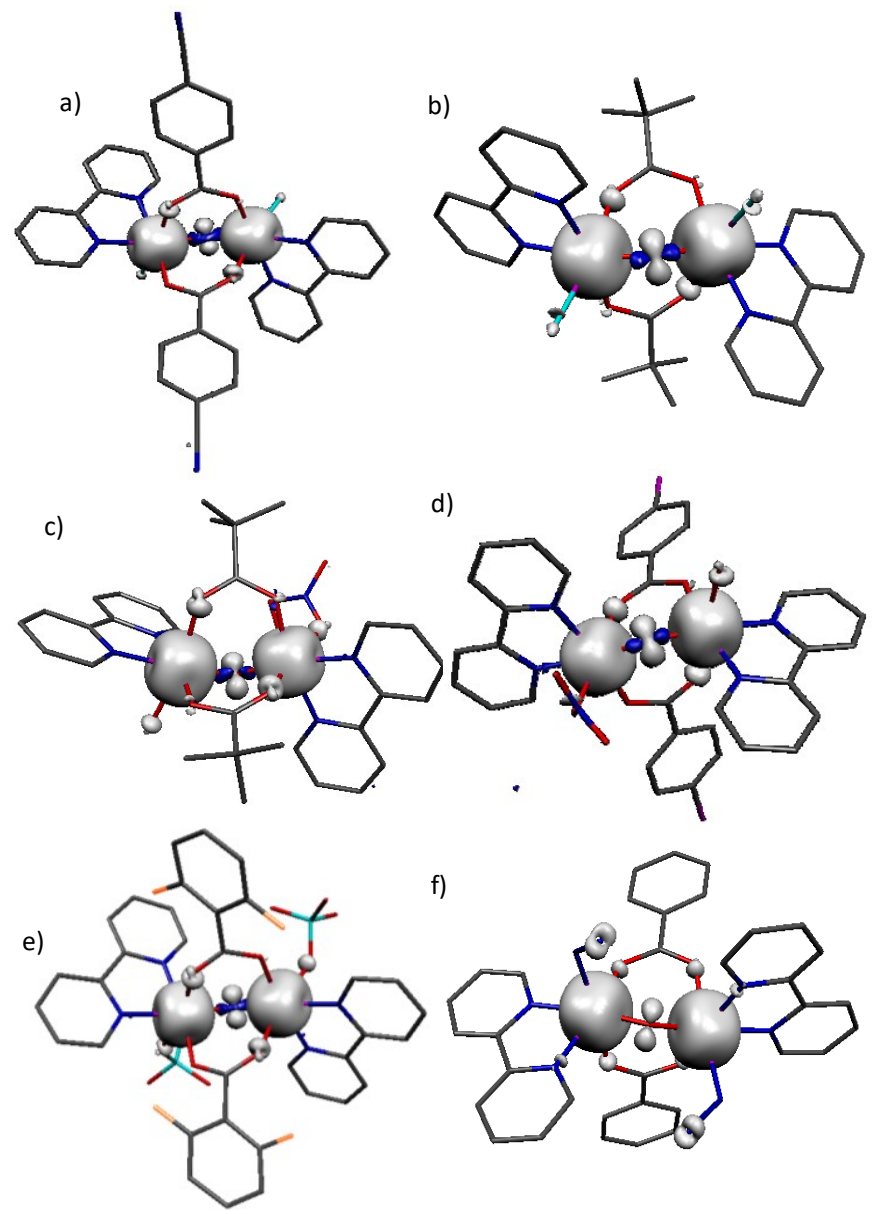

f)

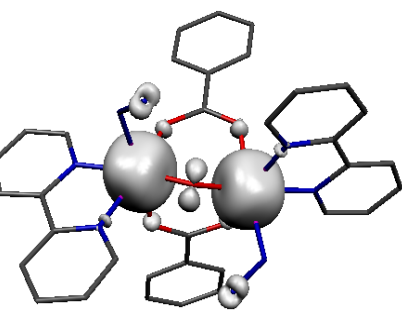

Figure 7. Computed spin density plots of the high-spin state for complexes a) 1; b) 2; c) 6; d) 7; e) $\mathbf{1 1}$ and f) $\mathbf{1 2}$. The isodensity surface represented corresponds to a value of $0.0043 \mathrm{e}^{-} \mathrm{bohr}^{-3}$. The white and blue regions indicate the positive and negative spin densities, respectively.

\section{Magneto-Structural Correlations}

As mentioned earlier the orientation of the Jahn-Teller axis is the significant parameter in controlling the $J$ values in the reported $\mathrm{Mn}^{\prime \prime \prime}$ dinuclear complexes, however if the JT angles are similar for a set of structures, other structural parameters are likely to influence the sign and magnitude of $J$. To ascertain this aspect, we have developed magneto-structural correlation by varying several related structural parameters vs. $J$ values. Here magneto-structural correlations are developed for the $\mathrm{Mn}-\mathrm{O}-\mathrm{Mn}$ angle and the $\mathrm{Mn}-\mathrm{O}$ distance for complexes $\mathbf{3}$ and $\mathbf{1 1}$ to see if these are important parameter in governing the strength of $J$ values. To develop the 
magneto-structural correlation for the $\mathrm{Mn}-\mathrm{O}$ distances and $\mathrm{Mn}-\mathrm{O}-$ $\mathrm{Mn}$ angles, the $\mathrm{Mn}-\mathrm{O}-\mathrm{Mn}$ and $\mathrm{Mn}-\mathrm{O}$ distances, respectively, are kept constant while $\mathrm{Mn}-\mathrm{Mn}$ distance is varied. It is important to note here that the correlation developed is specifically for type-IIIb structures as for the other three types, the relationship is likely to be different. ${ }^{60}$ The developed correlations for these two parameters are shown in Figure 8.

Bond distance: This correlation has been deduced by varying the average $\mathrm{Mn}-\mathrm{O}$ distances -1.49 to $2.09 \AA$ for both $\mathbf{3}$ and $\mathbf{1 1}$. This parameter shows an exponential relationship (See Figure 8, top) and the set of parameters used to fit is given in Table S16. With increasing distances, the $J$ value becomes strongly ferromagnetic and with decreasing distances it becomes moderately antiferromagnetic. Since there is a switch from antiferromagnetic to ferromagnetic, the $\mathrm{Mn}-\mathrm{O}$ distance is considered as an essential parameter to govern the $J$ values in these $\mathrm{Mn}^{\text {III }}$ dinuclear complexes along with the JT dihedral angle. At larger $\mathrm{Mn}-\mathrm{O}$ distances, the overlap between the two $\mathrm{Mn}^{\text {III }}$ ions diminish, leading to a weak ferromagnetic coupling. For type-I structures a similar relationship is noted, however the magnitude of the $J$ values are different. ${ }^{60}$
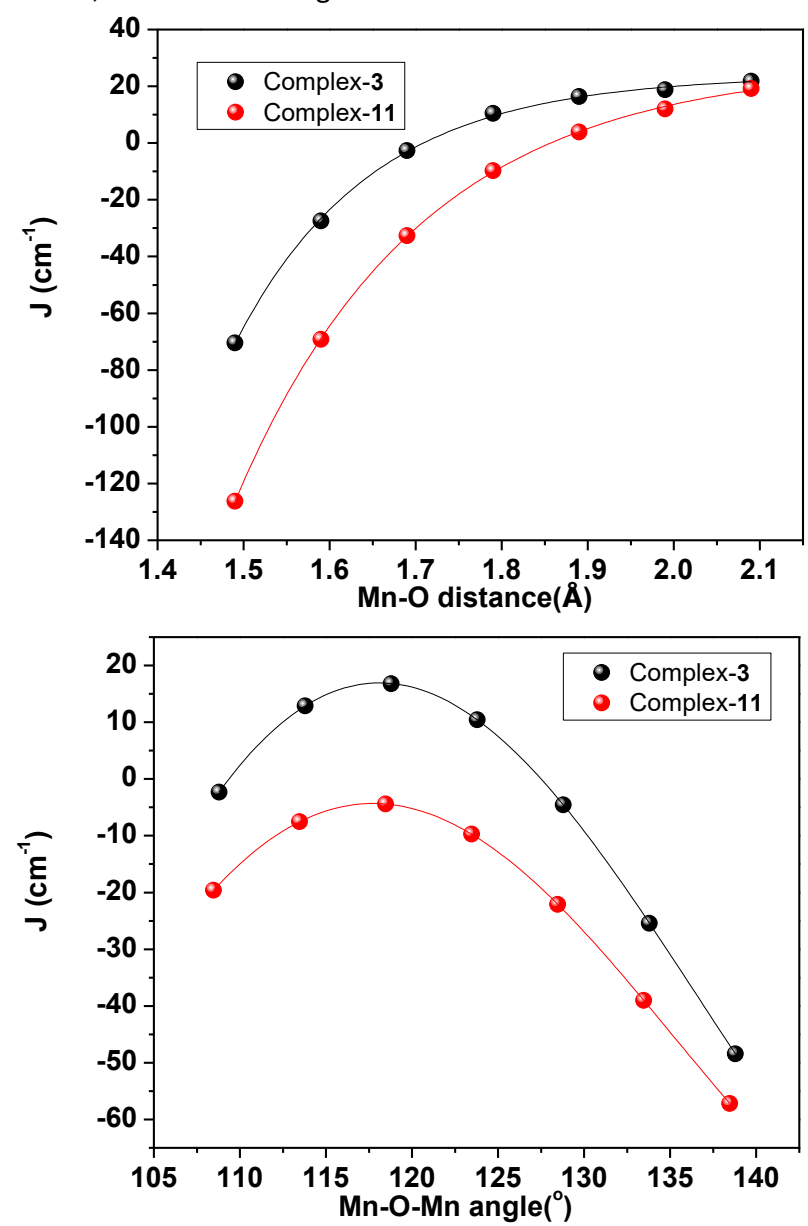

Figure 8. Magneto-structural correlations developed by varying structural parameters (top) $\mathrm{Mn}-\mathrm{O}$ distance and (bottom) Mn-O-Mn angle and using DFT calculations.

Bond angle: A correlation is developed by varying the $\mathrm{Mn}-\mathrm{O}-\mathrm{Mn}$ angle from $108.8^{\circ}$ to $138.8^{\circ}$ for complex 3 and $108.5^{\circ}$ to $138.5^{\circ}$ for complex 11. At shorter and larger $\mathrm{Mn}-\mathrm{O}-\mathrm{Mn}$ angles the $J$ parameter displays weak and moderate antiferromagnetic coupling, respectively, for both complexes. The curve shows a parabolic relationship (See Figure 8, bottom) and the set of parameters used to obtain the fit is given in Table S13. The weak antiferromagnetic interaction at smaller angle has been observed due to weak overlap of the $d_{x z} \mid d_{x z}$ and $d_{y z} \mid d_{y z}$ orbitals (See Table S14). However, at large angles the strong overlap between $d_{x z} \mid d_{x z}$ orbitals is observed leading to larger negative $J$ values (See Table S15). This correlation is contrary to the correlation found for type-I complexes, where increasing the $\mathrm{Mn}-\mathrm{O}-\mathrm{Mn}$ angle is found to decrease the $\mathrm{J}$ value leading to weak ferromagnetic coupling at higher angles. ${ }^{60}$

\section{Estimation of Zero field splitting parameters}

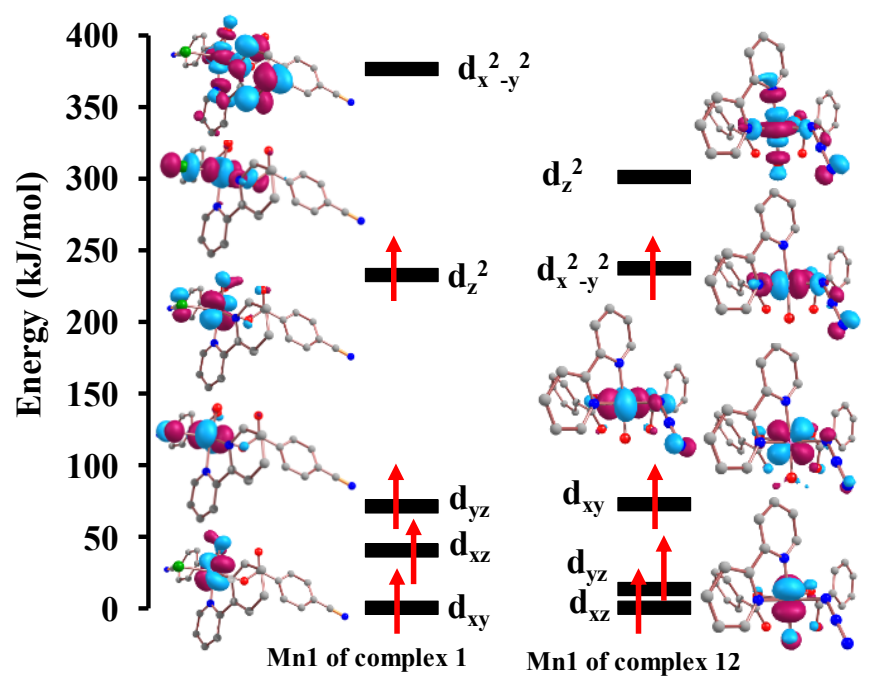

Figure 9. Computed d-orbitals splitting of $\mathrm{Mn}^{\prime \prime \prime}$ ions in $\mathbf{1}$ and $\mathbf{1 2 .}$

Ab initio CASSCF calculations on 1-12 have been made using the ORCA 3.0 suite of programs (see computational details) in order to determine the single ion anisotropy for each $\mathrm{Mn}^{\text {III }}$ site, as well as of the cluster anisotropy. As expected, the single ion $\mathrm{Mn}^{\text {III }}$ anisotropy yielded a large zfs parameter $(D)$. CASSCF calculations reveal $D$ values ranging from $-3.71 \mathrm{~cm}^{-1}$ to $-2.84 \mathrm{~cm}^{-1}$, with a small $E / D$ ratio for 1-11 (See Tables 3 and S3 in ESI). These values are in line with those expected for $\mathrm{Mn}^{\mathrm{III}}$ ions, a consequence of the Jahn-Teller distorted octahedral geometries. ${ }^{94-96}$ We have analysed the origin of the negative $D$ value of each $\mathrm{Mn}^{\prime \prime \prime}$ ion in 1-11 and the positive $D$ value of both $\mathrm{Mn}^{\text {III }}$ ions in $\mathbf{1 2}$ using orbital splitting diagrams and electron transitions in those orbitals. Here, we describe the origin of the zfs parameter for a $\mathrm{Mn}^{\mathrm{III}}$ ion of complex 1 (See Figure 9, left), which is representative of all $\mathrm{Mn}^{\prime \prime \prime}$ ions found in 1-11 and a $\mathrm{Mn}^{\prime \prime \prime}$ ion of 12 (See Figure 9, right). The computed orbital energy level for $\mathrm{Mn} 1$ of complex $\mathbf{1}$ and $\mathbf{1 2}$ is shown in Figure 9. Calculations reveal the following ground state electronic configuration for the JT elongated $\mathrm{Mn}(\mathrm{III})$ ion in 1: $\left(\mathrm{d}_{\mathrm{xy}}\right)^{1},\left(\mathrm{~d}_{\mathrm{xz}}\right)^{1},\left(\mathrm{~d}_{\mathrm{yz}}\right)^{1},\left(\mathrm{~d}_{\mathrm{z}}{ }^{2}\right)^{1}$ and $\left(\mathrm{d}_{\mathrm{x}}{ }^{2}-\mathrm{y}^{2}\right)^{0}$ and for the JT compressed Mn(III) ion in 12: $\left(d_{x z}\right)^{1},\left(d_{y z}\right)^{1},\left(d_{x y}\right)^{1},\left(d_{x}{ }^{2}-y^{2}\right)^{1}$ and $\left(d_{z}{ }^{2}\right)^{0}$. In particular, these configurations certainly support that in axially elongated complexes the $d_{x}{ }^{2}-y^{2}$ orbital is empty resulting in the zfs parameter $D<0$, and in axially compressed complexes the 
$\mathrm{d}_{\mathrm{z}}{ }^{2}$ orbital is empty, resulting in $\mathrm{D}>0$ same as previously reported. ${ }^{97-98}$ Moreover, the energy gap between the $\mathrm{e}_{\mathrm{g}}$ magnetic orbital is large for elongated case, whereas it is small for the compressed one. The same orbital splitting as Mn1 of complex 1 is observed of all $\mathrm{Mn}^{\text {III }}$ ions in 1-11, which therefore lead to a negative $D$ value. In contrast, in $\mathbf{1 2}$, both $\mathrm{Mn}^{\mathrm{II}}$ ions yield a positive $D$ value and this is due to the presence of Jahn-Teller compression (See Tables 3 and S3).

Additionally, using the CASSCF approach the zero-field splitting of the $S=4$ state is also estimated for the ferromagnetically coupled complexes, 3-4, 6, 9 and 12 (see Table 3). Quite interestingly, for dinuclear $\left\{\mathrm{Mn}^{\prime \prime \prime}{ }_{2}\right\}$ complexes, the overall $D_{S=4}$ is found to be positive varying from $+0.91 \mathrm{~cm}^{-1}$ to $1.17 \mathrm{~cm}^{-1}$. This is surprising, as the individual single-ion anisotropy is found to be negative for all cases, except for 12. While a similar scenario has been noted for a $\left\{\mathrm{Cr}_{12}\right\}$ polynuclear cluster, ${ }^{84}$ and also been predicted using theory on ferromagnetically coupled $\{\mathrm{MnCu}\}$ systems, ${ }^{99}$ such a dramatic switch in sign is unparalleled.

Table 3. Calculated cluster, single-ion and exchange anisotropy $D$

\begin{tabular}{|c|c|c|c|c|c|}
\hline Complexes & $\boldsymbol{D}_{\mathrm{s}=4}$ & $\boldsymbol{D}_{\mathrm{Mn} 1}$ & $\boldsymbol{D}_{\mathrm{Mn} 2}$ & $\boldsymbol{D}_{\mathrm{Mn} 1 \mathrm{Mn} 2}$ & $E / \boldsymbol{D}$ \\
$\mathbf{1}$ & -- & -3.05 & -2.93 & -- & -- \\
$\mathbf{2}$ & -- & -2.87 & -2.84 & -- & -- \\
$\mathbf{3}$ & 1.16 & -3.05 & -3.25 & 8.80 & 0.20 \\
$\mathbf{4}$ & 1.17 & -2.96 & -3.03 & 8.57 & 0.16 \\
$\mathbf{5}$ & -- & -3.29 & -3.15 & -- & -- \\
$\mathbf{6}$ & 1.09 & -3.17 & -3.41 & 8.75 & 0.21 \\
$\mathbf{7}$ & -- & -3.23 & -3.28 & -- & -- \\
$\mathbf{8}$ & -- & -2.93 & -2.92 & -- & -- \\
$\mathbf{9}$ & 0.98 & -3.29 & -3.19 & 8.28 & 0.16 \\
$\mathbf{1 0}$ & -- & -3.34 & -3.34 & -- & -- \\
$\mathbf{1 1}$ & -- & -3.23 & -3.23 & -- & -- \\
$\mathbf{1 2}$ & 0.91 & 3.72 & 3.69 & -2.38 & 0.13 \\
\hline
\end{tabular}

values for complexes 1-12 with E/D value of overall cluster.

To probe the reason of sign switch, we decided to analyse its origin. The axial-zero field splitting of the coupled $S=4$ state for the dimer is given by the following equation: ${ }^{100}$

$D_{S=4}=d_{M n 1} D_{M n 1}+d_{M n 2} D_{M n 2}+d_{M n 1 M n 2} D_{M n 1 M n 2} \ldots . .$. Eq.

in which $\left(D_{\mathrm{Mn} 1}\right.$ or $\left.D_{\mathrm{Mn} 2}\right)$ and $D_{\mathrm{Mn} 1 \mathrm{Mn} 2}$ are the single-ion and exchange anisotropies, respectively, and $d_{M n 1}=d_{M n 2}=3 / 14$ and $d_{M n 1 M n 2}=2 / 7$ are the corresponding coefficients reported for solving the equation for the zfs. ${ }^{100}$ This equation is applicable only when the $D_{\mathrm{zz}}$ axis are parallel and thus it is suitable for this class of molecules. In this equation, $D_{\mathrm{Mn} 1}, D_{\mathrm{Mn} 2}$ and $D_{s=4}$ are known from $a b$ initio calculations which allows us to estimate the exchange contribution to the anisotropy $D_{\mathrm{Mn} 1 \mathrm{Mn} 2}$. The exchange anisotropy $D_{\mathrm{Mn} 1 \mathrm{Mn} 2}$ has two contributions (i) through space - the dipolar contribution and (ii) through bond - the exchange contribution. ${ }^{101}$ Our calculations produce a very large $D_{\mathrm{Mn} 1 \mathrm{Mn} 2}$ contribution in the range of $-2.38 \mathrm{~cm}^{-1}$ to $+8.8 \mathrm{~cm}^{-1}$. Interestingly, for complex 12 , where single-ion anisotropy is found to be positive, the $D_{\mathrm{Mn} 1 \mathrm{Mn} 2}$ contribution is estimated to be negative. Thus, unusually, an antagonizing behaviour of $D_{\mathrm{Mn}}$ and $D_{\mathrm{Mn} 1 \mathrm{Mn} 2}$ are noted for this set of complexes. Here the large exchange contributions are found to overshadow the single-ion anisotropy and decisively control the sign of $D$ value in the dinuclear framework. While such a large contribution is unprecedented, a very large contribution to the magnetic anisotropy arising from exchange has also been noted for a tetranuclear $\left\{\mathrm{VFe}_{3}\right\}$ cluster. ${ }^{102}$

While the single-ion anisotropy of the transition metal ion and, to some extent, the cluster anisotropy of the ground state of several manganese clusters are established, how various factors influence the ground state anisotropy is poorly explored. There is a general belief that the incorporation of the Jahn-Teller elongated $\mathrm{Mn}^{\text {"II }}$ ion is likely to induce negative anisotropy in the cluster frame work and if this is coupled with ferromagnetic coupling, one is likely to obtain SMM behaviour. While there is ample literature evidence where a very large spin ground state and zero or positive $D$ contributions are noted for several Mn"II clusters, how various contributions play out to control the ground state anisotropy is not thoroughly explored. Our study clearly reveals that, for both compressed and elongated JT structures, the two contributions to the anisotropy are antagonizing each other, leading to a net positive $D$ value for each complex. A thorough and rigorous analysis on the various contributing factors to the anisotropy is needed to judge suitable building units for the design of SMMs in the future.

\section{Conclusions}

A new family of $\mu$-oxo $\mu$-dicarboxylato-bridged $\mathrm{Mn}^{\text {III }}$ dimers have been synthesised, characterized and analysed using various theoretical techniques. All twelve structures reported belong to type IIIb Mn"I dimer complexes (see Figure 4), where the exchange interactions show moderate ferro- and antiferromagnetic interactions. The magnitude of the exchange is found to vary between $-9.73 \mathrm{~cm}-1$ to $+19.23 \mathrm{~cm}^{-1}$ by the DFT prediction, which is corroborated via the experimental magnetic data. In seven complexes, the $\mathrm{Mn}^{\text {III }}$ centres are antiferromagnetically coupled and in the other five complexes, the $\mathrm{Mn}^{\text {III }}$ centres are ferromagnetically coupled to each other. Theoretical studies were undertaken to investigate the origin of the differences in the observed magnetic behaviour. The orbital overlaps have been analysed using overlap integral computation which revealed that the overlap between the $d_{x z}$ or $d_{y z}$ orbitals leads to an antiferromagnetic interaction. The negligible overlap between the $d_{x z}$ or $d_{y z}$ orbitals lead to a ferromagnetic interaction. Furthermore, the JT dihedral angle plays pivotal role in the variation of magnitude of exchange interaction. In the field of SMMs a strong ferromagnetic interaction is highly preferred, as this maximizes the magnitude of the ground state $S$ value and the energy separation to the first excited state.

We have also computed the zero-field splitting of the $S=4$ state for the ferromagnetically coupled complexes $(3,4,6,9$ and 12$)$ and the calculations reveal net positive $D$ values for all cases, which is 
essentially due to the perpendicular orientation of the Jahn-Teller axes. Here, the single-ion and the exchange anisotropy contributions are found to be antagonizing each other, both in the JT compressed (complex 12) and elongated cases (complex 3, 4, 6 and 9), leading to a net positive $D$ value. While our study sadly reveals that obtaining a negative zero-field splitting parameter in ferromagnetic $\mathrm{Mn}^{\text {III }}$ clusters is cumbersome, fine tuning the otherwise ignored parameter: the exchange anisotropy may hold the clue to obtain net negative $D$ parameters and thus may pave a way forward for new generation SMMs based on $\mathrm{Mn}^{\text {III }}$ ions.

\section{Conflicts of interest}

There are no conflicts to declare.

\section{Acknowledgements}

The authors would like to thank Dr Wasinee Phonsri and Ethan Watkins for help with synthesis and crystal growing and Dr Brendan Abrahams for crystallographic assistance. GR would like to thank SERB (EMR/2014/000247) for the funding. KSM would like to thank the Australian Research Council for funding. KRV would like to thank the IITB-Monash Academy for research funding and IITB for generous high performance computing facilities.

\section{References}

1 O. Kahn, Angew. Chem. Int. Ed., 1985, 24, 834-850.

2 R. Sessoli, D. Gatteschi, A. Caneschi and M. A. Novak, Nature, 1993, 365, 141-143.

3 R. Sessoli, H. L. Tsai, A. R. Schake, S. Wang, J. B. Vincent, K. Folting, D. Gatteschi, G. Christou and D. N. Hendrickson, J. Am. Chem. Soc., 1993, 115, 1804-1816.

4 D. Gatteschi, R. Sessoli and J. Villain, Molecular Nanomagnets, Oxford University Press, Oxford, 2006.

5 D. Gatteschi, Adv. Mater., 1994, 6, 635-645.

6 J. Mater. Chem., 2009, 19, 1670-1671.

7 M. N. Leuenberger and D. Loss, Nature, 2001, 410, 789-793.

8 M. Evangelisti and E. K. Brechin, Dalton Trans., 2010, 39, 4672 4676.

9 G. Karotsis, S. Kennedy, S. J. Teat, C. M. Beavers, D. A. Fowler, J. J. Morales, M. Evangelisti, S. J. Dalgarno and E. K. Brechin, J. Am. Chem. Soc., 2010, 132, 12983-12990.

10 L. Bogani and W. Wernsdorfer, Nat. Mater., 2008, 7, 179-186.

11 E. D. Estes, W. E. Hatfield and D. J. Hodgson, Inorg. Chem., 1974, 13, 1654-1657.

12 W. E. Hatfield, in Extended Interactions between Metal Ions, ACS, 1974 , vol. 5, ch. 10, pp. 108-141.

13 D. L. Lewis, K. T. McGregor, W. E. Hatfield and D. J. Hodgson, Inorg. Chem., 1974, 13, 1013-1019.

14 K. T. McGregor, N. T. Watkins, D. L. Lewis, R. F. Drake, D. J. Hodgson and W. E. Hatfield, Inorg. Nucl. Chem. Lett., 1973, 9, 423-428.

15 S. M. Gorun and S. J. Lippard, Inorg. Chem., 1991, 30, 16251630.

16 H. Weihe and H. U. Güdel, J. Am. Chem. Soc., 1997, 119, 65396543.
17 H. Weihe and H. U. Güdel, J. Am. Chem. Soc., 1998, 120, 28702879.

18 S. J. Cline, D. J. Hodgson, S. Kallesoe, S. Larsen and E. Pedersen, Inorg. Chem., 1983, 22, 637-642.

19 W. E. Hatfield, J. J. MacDougall and R. E. Shepherd, Inorg. Chem., 1981, 20, 4216-4219.

20 D. J. Hodgson, NATO ASI Ser., Ser. C 1985, 140, 497-522.

21 R. P. Scaringe, D. J. Hodgson and W. E. Hatfield, Transition Met. Chem., 1981, 6, 340-344.

22 T. K. Karmakar, B. K. Ghosh, A. Usman, H.-K. Fun, E. Rivière, T. Mallah, G. Aromí and S. K. Chandra, Inorg. Chem., 2005, 44, 2391-2399.

23 D. A. Pantazis, V. Krewald, M. Orio and F. Neese, Dalton Trans., 2010, 39, 4959-4967.

24 E. Ruiz, S. Alvarez, A. Rodríguez-Fortea, P. Alemany, Y. Pouillon and C. Massobrio, in Magnetism: Molecules to Materials, WileyVCH Verlag GmbH \& Co. KGaA, 2004, DOI: 10.1002/9783527620548.ch7a, pp. 227-279.

25 S. V. Antonyuk, V. R. Melik-Adamyan, A. N. Popov, V. S. Lamzin, P. D. Hempstead, P. M. Harrison, P. J. Artymyuk and V. V. Barynin, Crystallogr. Rep., 2000, 45, 105-116.

26 V. V. Barynin, M. M. Whittaker, S. V. Antonyuk, V. S. Lamzin, P. M. Harrison, P. J. Artymiuk and J. W. Whittaker, Structure, 2001, 9, 725-738.

27 M. M. Whittaker, V. V. Barynin, S. V. Antonyuk and J. W. Whittaker, Biochemistry, 1999, 38, 9126-9136.

28 V. Gómez, M. Corbella and G. Aullón, Inorg. Chem., 2010, 49, $1471-1480$.

29 M. Corbella, R. Costa, J. Ribas, P. H. Fries, J.-M. Latour, L. Öhrström, X. Solans and V. Rodríguez, Inorg. Chem., 1996, 35, 1857-1865.

30 J. B. Vincent, H. L. Tsai, A. G. Blackman, S. Wang, P. D. W. Boyd, K. Folting, J. C. Huffman, E. B. Lobkovsky, D. N. Hendrickson and G. Christou, J. Am. Chem. Soc., 1993, 115, 12353-12361.

31 R. Hotzelmann, K. Wieghardt, U. Floerke, H. J. Haupt, D. C. Weatherburn, J. Bonvoisin, G. Blondin and J. J. Girerd, J. Am. Chem. Soc., 1992, 114, 1681-1696.

32 G. Fernández, M. Corbella, M. Alfonso, H. Stoeckli-Evans and I. Castro, Inorg. Chem., 2004, 43, 6684-6698.

33 C. Cañada-Vilalta, W. E. Streib, J. C. Huffman, T. A. O'Brien, E. R. Davidson and G. Christou, Inorg. Chem., 2004, 43, 101-115.

34 F. J. Wu, D. M. Kurtz, K. S. Hagen, P. D. Nyman, P. G. Debrunner and V. A. Vankai, Inorg. Chem., 1990, 29, 5174-5183.

35 M. Corbella, V. Gómez, B. Garcia, E. Rodriguez, B. Albela and M. A. Maestro, Inorg. Chim.Acta., 2011, 376, 456-462.

36 V. Gomez, M. Corbella, O. Roubeau and S. J. Teat, Dalton Trans., 2011, 40, 11968-11975.

37 C. Chen, H. Zhu, D. Huang, T. Wen, Q. Liu, D. Liao and J. Cui, Inorg. Chim.Acta., 2001, 320, 159-166.

38 J. B. Vincent, K. Folting, J. C. Huffman and G. Christou, Biochem. Soc. Trans., 1988, 16, 822-823.

39 K. Mitra, D. Mishra, S. Biswas, C. R. Lucas and B. Adhikary, Polyhedron, 2006, 25, 1681-1688.

40 S. Menage, J.-J. Girerd and A. Gleizes, J. Chem. Soc. Chem. Commun., 1988, 0, 431-432.

41 J. E. Sheats, R. S. Czernuszewicz, G. C. Dismukes, A. L. Rheingold, V. Petrouleas, J. Stubbe, W. H. Armstrong, R. H. Beer and S. J. Lippard, J. Am. Chem. Soc., 1987, 109, 1435-1444.

42 C. Bolm, N. Meyer, G. Raabe, T. Weyhermuller and E. Bothe, Chem. Commun., 2000, 0, 2435-2436.

43 T. K. Lal and R. Mukherjee, Inorg. Chem., 1998, 37, 2373-2382. 
44 S. Mahapatra, T. K. Lal and R. Mukherjee, Inorg. Chem., 1994, 33, 1579-1580.

45 K. Wieghardt, U. Bossek, D. Ventur and J. Weiss, J. Chem. Soc. Chem. Commun., 1985, 0, 347-349.

46 B. Albela, M. Corbella and J. Ribas, Polyhedron, 1996, 15, 91-96.

47 K. R. Reddy, M. V. Rajasekharan and S. Sukumar, Polyhedron, 1996, 15, 4161-4168.

48 R. Ruiz, C. Sangregorio, A. Caneschi, P. Rossi, A. B. Gaspar, J. A. Real and M. C. Muñoz, Inorg. Chem. Commun., 2000, 3, 361367.

49 B. C. Dave and R. S. Czernuszewicz, Inorg. Chim.Acta., 1998, 281, 25-35.

50 G. Fernández, M. Corbella, G. Aullón, A. Maestro Miguel and J. Mahía, Eur. J. Inorg. Chem., 2007, 2007, 1285-1296.

51 G. Aromí and E. K. Brechin, in Struct. Bond., 2006, vol. 122, pp. 1-67.

52 M. Atanasov, P. Comba, S. Helmle, D. Muller and F. Neese, Inorg. Chem., 2012, 51, 12324-12335.

53 M. Atanasov, J. M. Zadrozny, J. R. Long and F. Neese, Chem. Sci., 2013, 4, 139.

54 R. Boča, Coord. Chem. Rev., 2004, 248, 757-815.

55 S. Gomez-Coca, E. Cremades, N. Aliaga-Alcalde and E. Ruiz, J. Am. Chem. Soc., 2013, 135, 7010-7018.

56 S. Gomez-Coca, E. Cremades, N. Aliaga-Alcalde and E. Ruiz, Inorg. Chem., 2014, 53, 676-678.

57 K. E. R. Marriott, L. Bhaskaran, C. Wilson, M. Medarde, S. T. Ochsenbein, S. Hill and M. Murrie, Chem. Sci., 2015, 6, 68236828.

58 C. Duboc, D. Ganyushin, K. Sivalingam, M. N. Collomb and F. Neese, J. Phys. Chem. A, 2010, 114, 10750-10758.

59 W. P. Barros, R. Inglis, G. S. Nichol, T. Rajeshkumar, G. Rajaraman, S. Piligkos, H. O. Stumpf and E. K. Brechin, Dalton Trans., 2013, 42, 16510-16517.

60 N. Berg, T. Rajeshkumar, S. M. Taylor, E. K. Brechin, G. Rajaraman and L. F. Jones, Chem. Eur. J., 2012, 18, 5906-5918.

61 G. Sheldrick, Acta Crystallogr. Sect. A, 2015, 71, 3-8.

62 N. P. Cowieson, D. Aragao, M. Clift, D. J. Ericsson, C. Gee, S. J. Harrop, N. Mudie, S. Panjikar, J. R. Price, A. Riboldi-Tunnicliffe, R. Williamson and T. Caradoc-Davies, J. Synchrotron Radiat., 2015, 22, 187-190.

63 T. M. McPhillips, S. E. McPhillips, H.-J. Chiu, A. E. Cohen, A. M. Deacon, P. J. Ellis, E. Garman, A. Gonzalez, N. K. Sauter, R. P. Phizackerley, S. M. Soltis and P. Kuhn, J. Synchrotron Radiat., 2002, 9, 401-406.

64 W. Kabsch, J. Appl. Crystallogr., 1993, 26, 795-800.

65 CrysAlisPro, Oxford Diffraction Ltd., Version 1.171.133.134d (release 127-102-2009 CrysAlis2171.NET).

66 CrysAlisPro, Oxford Diffraction Ltd., Version 1.171.133.134d (release 127-102-2009 CrysAlis2171 .NET) Empirical absorption correction using spherical harmonics, implemented in SCALE2003 ABSPACK scaling algorithm.

67 G. Sheldrick, Acta Crystallogr. Sect. C, 2015, 71, 3-8.

68 A. Spek, Acta Crystallogr. Sect. C, 2015, 71, 9-18.

69 L. Noodleman, J. Am. Chem. Soc., 1981, 74, 5737-5743.

70 P. Christian, G. Rajaraman, A. Harrison, M. Helliwell, J. J. W. McDouall, J. Raftery and R. E. P. Winpenny, Dalton Trans., 2004, DOI: 10.1039/B407126C, 2550-2555.

71 S. Piligkos, G. Rajaraman, M. Soler, N. Kirchner, J. van Slageren, R. Bircher, S. Parsons, H.-U. Gudel, J. Kortus, W. Wernsdorfer, G. Christou and E. K. Brechin, J. Am. Chem. Soc., 2005, 127, 55725580.
72 G. Rajaraman, J. Cano, E. K. Brechin and E. J. L. McInnes, Chem. Commun., 2004, 0, 1476-1477.

73 E. Ruiz, J. Cano, S. Alvarez and P. Alemany, J. Comput. Chem. 1999, 20, 1391-1400.

74 E. Ruiz, J. Cano, S. Alvarez, A. Caneschi and D. Gatteschi, J. Am. Chem. Soc., 2003, 125, 6791-6794.

75 E. Ruiz, A. Rodríguez-Fortea, J. Cano, S. Alvarez and P. Alemany, J. Comput. Chem., 2003, 24, 982-989.

76 N. Berg, T. N. Hooper, J. Liu, C. C. Beedle, S. K. Singh, G. Rajaraman, S. Piligkos, S. Hill, E. K. Brechin and L. F. Jones, Dalton Trans., 2013, 42, 207-216.

77 S. Ghosh, S. K. Singh, S. Tewary and G. Rajaraman, Dalton Trans., 2013, 42, 16490-16493.

78 G. Rajaraman, M. Murugesu, E. C. Sanudo, M. Soler, W. Wernsdorfer, M. Helliwell, C. Muryn, J. Raftery, S. J. Teat, G. Christou and E. K. Brechin, J. Am. Chem. Soc., 2004, 126, 1544515457.

79 P. Christian, G. Rajaraman, A. Harrison, J. J. W. McDouall, J. T. Raftery and R. E. P. Winpenny, Dalton Trans., 2004, DOI: 10.1039/B404031G, 1511-1512.

80 E. Cremades, J. Cano, E. Ruiz, G. Rajaraman, C. J. Milios and E. K. Brechin, Inorg. Chem., 2009, 48, 8012-8019.

81 K. R. Vignesh, S. K. Langley, B. Moubaraki, K. S. Murray and G. Rajaraman, Chem. Eur. J., 2015, 21, 16364-16369.

82 K. R. Vignesh, S. K. Langley, K. S. Murray and G. Rajaraman, Chem. Eur. J., 2015, 21, 2881-2892.

83 K. R. Vignesh, S. K. Langley, B. Moubaraki, K. S. Murray and G. Rajaraman, Inorg. Chem., 2018, 57, 1158-1170.

84 D. Collison, M. Murrie, V. S. Oganesyan, S. Piligkos, N. R. J. Poolton, G. Rajaraman, G. M. Smith, A. J. Thomson, G. A. Timko, W. Wernsdorfer, R. E. P. Winpenny and E. J. L. Mclnnes, Inorg. Chem., 2003, 42, 5293-5303.

85 A. D. Becke, J. Chem. Phys., 1993, 98, 5648-5652.

86 M. J. Frisch, G. W. Trucks, H. B. Schlegel, G. E. Scuseria, M. A. Robb, J. R. Cheeseman, G. Scalmani, V. Barone, B. Mennucci, G. A. Petersson, H. Nakatsuji, M. Caricato, X. Li, H. P. Hratchian, A. F. Izmaylov, J. Bloino, G. Zheng, J. L. Sonnenberg, M. Hada, M. Ehara, K. Toyota, R. Fukuda, J. Hasegawa, M. Ishida, T. Nakajima, Y. Honda, O. Kitao, H. Nakai, T. Vreven, J. A. Montgomery, J. E. P. Jr., F. Ogliaro, M. Bearpark, J. J. Heyd, E. Brothers, K. N. Kudin, V. N. Staroverov, R. Kobayashi, J. Normand, K. Raghavachari, A. Rendell, J. C. Burant, S. S. lyengar, J. Tomasi, M. Cossi, N. Rega, J. M. Millam, M. Klene, J. E. Knox, J. B. Cross, V. Bakken, C. Adamo, J. Jaramillo, R. Gomperts, R. E. Stratmann, O. Yazyev, A. J. Austin, R. Cammi, C. Pomelli, J. W. Ochterski, R. L. Martin, K. Morokuma, V. G. Zakrzewski, G. A. Voth, P. Salvador, J. J. Dannenberg, S. Dapprich, A. D. Daniels, Ö. Farkas, J. B. Foresman, J. V. Ortiz, a. J. Cioslowski, D. J. Fox and I. Gaussian, Wallingford CT . Gaussian 09 (Revision A.02), 2009.

87 A. Schaefer, H. Horn and R. Ahlrichs, J. Chem. Phys., 1992, 97, 2571-2577.

88 A. Schaefer, C. Huber and R. Ahlrichs, J. Chem. Phys., 1994, 100, 5829-5835.

89 N. F. Chilton, R. P. Anderson, L. D. Turner, A. Soncini and K. S. Murray, J. Comput. Chem., 2013, 34, 1164-1175.

90 F. Neese, WIRES Comput. Mol. Sci., 2012, 2, 73-78.

91 F. Neese, T. Petrenko, D. Ganyushin and G. Olbrich, Coord. Chem. Rev., 2007, 251, 288-327.

92 K. R. Vignesh, S. K. Langley, C. J. Gartshore, B. Moubaraki, K. S. Murray and G. Rajaraman, Inorg. Chem., 2017, 56, 1932-1949.

93 Z.-Y. Zhang, C. Brouca-Cabarrecq, C. Hemmert, F. Dahan and J.P. Tuchagues, J. Chem. Soc. Dalton. Trans., 1995, 0, 1453-1460. 
94 J. Cirera, E. Ruiz, S. Alvarez, F. Neese and J. Kortus, Chem. Eur. J., 2009, 15, 4078-4087.

95 R. Maurice, C. de Graaf and N. Guihery, J. Chem. Phys., 2010, 133, 084307-084312.

96 S. Sanz, J. M. Frost, T. Rajeshkumar, S. J. Dalgarno, G. Rajaraman, W. Wernsdorfer, J. Schnack, P. J. Lusby and E. K. Brechin, Chem. Eur. J., 2014, 20, 3010-3013.

97 J. Krzystek, G. J. Yeagle, J.-H. Park, R. D. Britt, M. W. Meisel, L.-C. Brunel and J. Telser, Inorg. Chem., 2003, 42, 4610-4618.

98 F. Neese, J. Am. Chem. Soc., 2006, 128, 10213-10222.

99 S. K. Singh and G. Rajaraman, Chem. Eur. J., 2014, 20, 52145218.

100 A. Bencini and D. Gatteschi, in Electron Paramagnetic Resonance of Exchange Coupled Systems, Springer, 2011.

101 P. ter Heerdt, M. Stefan, E. Goovaerts, A. Caneschi and A. Cornia, J. Magn. Reson., 2006, 179, 29-37.

102 M. Westrup Kátia Cristina, M. E. Boulon, P. Totaro, G. Nunes Giovana, F. Back Davi, A. Barison, M. Jackson, C. Paulsen, D. Gatteschi, L. Sorace, A. Cornia, F. Soares Jaísa and R. Sessoli, Chem. Eur. J., 2014, 20, 13681-13691.

\section{Table of Contents}

A family of twelve dinuclear manganese(III) complexes containing $\mu$ oxo-di- $\mu$-carboxylato bridges has been investigated by structuremagnetism correlations and by density functional theory to deduce 
the magnitude and the origin of exchange coupling and zero-field splitting.

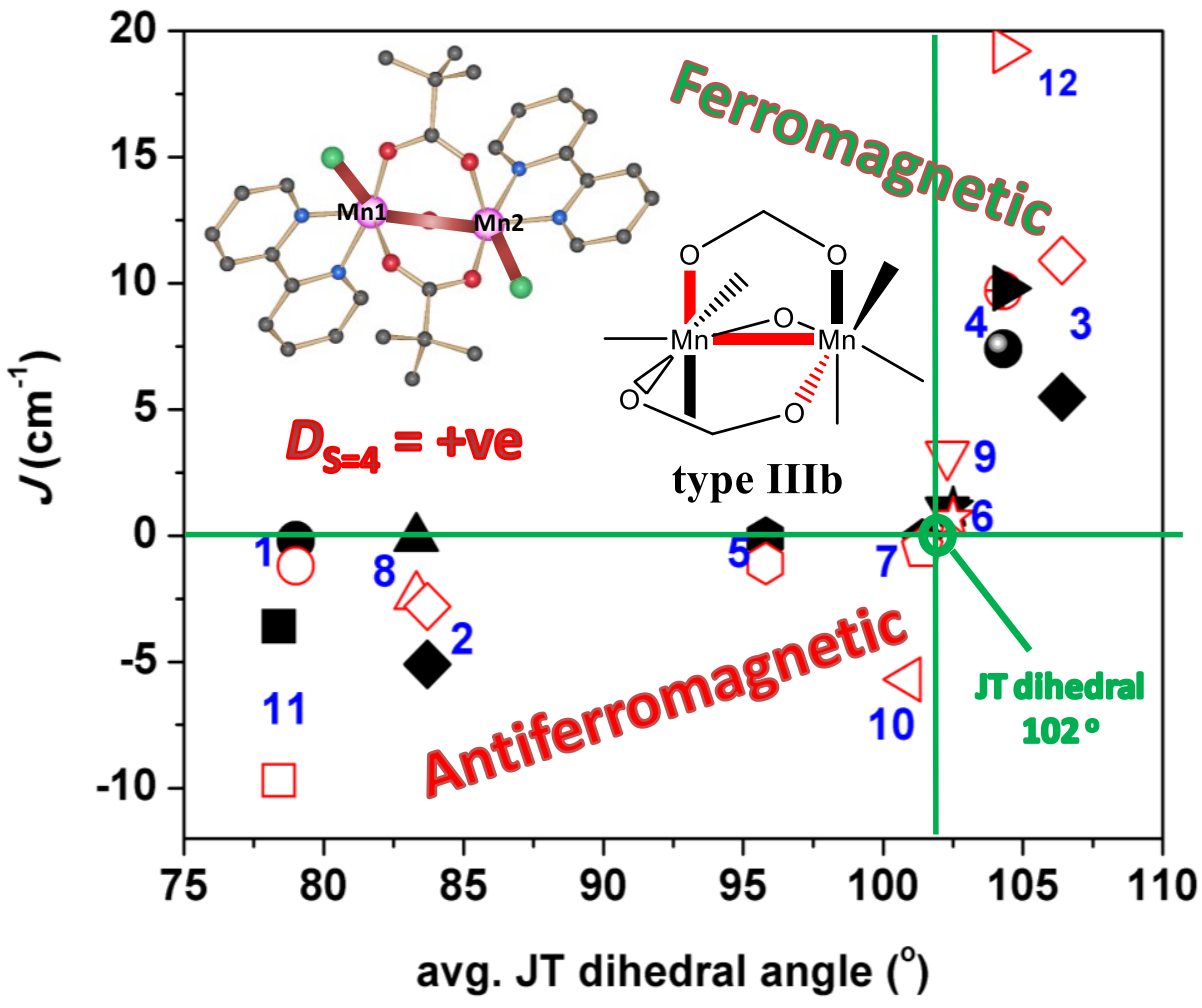

